\title{
An Investigation of Trait Aggression: Its Relationship with Reported Injuries and Moral Disengagement
}

Joseph N. Martinez

West Virginia University

Follow this and additional works at: https://researchrepository.wvu.edu/etd

\section{Recommended Citation}

Martinez, Joseph N., "An Investigation of Trait Aggression: Its Relationship with Reported Injuries and Moral Disengagement" (2011). Graduate Theses, Dissertations, and Problem Reports. 4751.

https://researchrepository.wvu.edu/etd/4751

This Thesis is protected by copyright and/or related rights. It has been brought to you by the The Research Repository @ WVU with permission from the rights-holder(s). You are free to use this Thesis in any way that is permitted by the copyright and related rights legislation that applies to your use. For other uses you must obtain permission from the rights-holder(s) directly, unless additional rights are indicated by a Creative Commons license in the record and/ or on the work itself. This Thesis has been accepted for inclusion in WVU Graduate Theses, Dissertations, and Problem Reports collection by an authorized administrator of The Research Repository @ WVU. For more information, please contact researchrepository@mail.wvu.edu. 
An Investigation of Trait Aggression: Its Relationship with Reported Injuries and Moral Disengagement

Joseph N. Martinez, ATC

Thesis submitted to the

College of Physical Activities and Sport Sciences at West Virginia University in partial fulfillment of the requirements for the degree of

Master of Science

in

Athletic Training

Damien Clement, Ph.D., ATC, Chair

Vanessa Shannon, Ph.D.

Michele Kabay, M.Ed, ATC

Department of Sport Sciences

Morgantown, WV

2011

Keywords: Aggressiveness, Injury Rate, Moral Disengagement, Injured Athletes 


\begin{abstract}
An Investigation of Trait Aggression: Its relationship with Reported Injuries and Moral Disengagement
\end{abstract}

Joseph N. Martinez

Objective: To examine the potential relationship that exists between the level of aggressiveness and the number of injuries reported during the course of a season. The secondary analysis will determine whether aggressiveness is related to moral disengagement. Background: There are a number of factors that exist that may predispose an athlete to sustaining an injury during participation in sports. According to the researchers Anderson and Bushman innate personality factors may play a role in the event of an injury. One factor that has not been thoroughly examined in the literature is aggressiveness in athletes, which is essentially the personality trait of acting aggressively. Since this factor could potentially be modifiable through an intervention involving both the athletic training staff and a trained sports psychology professional further researcher is necessary. In addition to injury rate, aggressiveness has been negatively implicated in moral reasoning. Theorized by Bandura, moral disengagement, is composed of eight individual mechanisms which allow the individual to free themselves of having to accept blame for transgressions. The eight processes of moral disengagement are moral justification, euphemistic labeling, advantageous comparison, displacement of responsibility, diffusion of responsibility, distortion of consequences, dehumanization, and finally attribution of blame. Design and Setting: A convenience sample was utilized for the data collection using athletes at Division III Mid-Atlantic University. The coaches of various teams at the school were contacted to inquire whether they would allow their athletes to participate in the current study. The data was collected during team meetings, spring practices, and prior to team lifting sessions. Packets containing the Competitive Anger and Aggressiveness Scale (CAAS), the Moral Disengagement in Sport Scale (MDSS), and a demographics questionnaire were distributed to the participants. The number of injuries sustained during the most recent season were counted and recorded. Participants: A total of 116 athletes participated in the study involved in a variety of sports including the football team $(n=73)$, men's basketball $(n=12)$, women's basketball $(n=5)$, men's soccer $(n=21)$, and women's soccer $(n=5)$. All collegiate levels were represented by the sample population with an age range of 18 to 26 years old $(M=$ $19.655, S D=1.326$ ). Results: A positive significant weak correlation was determined to exist between the number of reported injuries and the aggressiveness scale on the CAAS $(r(116)=0.216 ; p=0.02)$. Positive correlations were found to exist between aggressiveness on the CAAS and the subscales of the MDSS: Conduct Reconstrual $(r$ (116) $=0.598 ; p<0.001)$, Advantageous Comparison $(r(116)=0.481 ; p<0.001)$, Non-responsibility, $(r(116)=0.448 ; p<0.001)$, Distortion of Consequences $(r(116)=$ $0.516 ; p<0.001)$, Dehumanization $(r(116)=0.558 ; p<0.001)$, and finally Attribution of Blame $(r(116)=0.407, p<0.001)$. Conclusions: The findings of this research may allow athletic trainers and other members of the sports medicine department prevent injuries for those athletes that have been identified as acting aggressively by intervening through various methods. 


\section{ACKNOWLEDGEMENTS}

There are some people that deserve my gratitude and acknowledgement for their assistance and support:

Mom and Dad - I couldn't have accomplished all that I've done of this without your support and encouragement. Thanks for always being my biggest fans.

Matt and Kara - Thanks for pretending to be interested in this when I was explaining this to you guys. You got a shout out in the beginning just for listening.

Vilija "Wheezy" Bishop - "You know what I do for adventure? Go hang gliding on a Dorito" Thank you for everything because you don't know how much it helped.

Amy Tible - Thank you for listening and offering your assistance and encouragement whenever possible. You're a lifesaver.

My roommates - Thanks for helping me up when gravity won and not laughing.

Dr. Clement - Without your assistance and direction this thesis work would have never gotten done.

Michele Kabay and Dr. Shannon - Thank you for your contributions and insights while I was performing this study.

My students - Thanks.

The athletes and coaches - Without you this research definitely would not have been possible. Thank you.

Thank you again to all of you for your support and dedication. 


\section{TABLE OF CONTENTS}

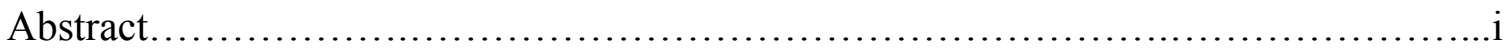

Acknowledgements...........................................................

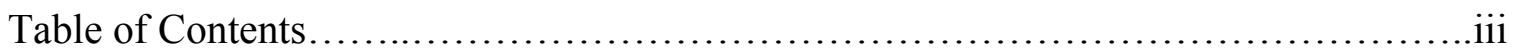

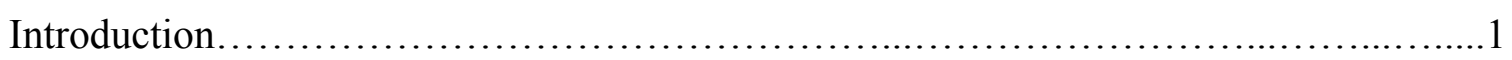

Methods........................................................................ 8

Participants............................................................

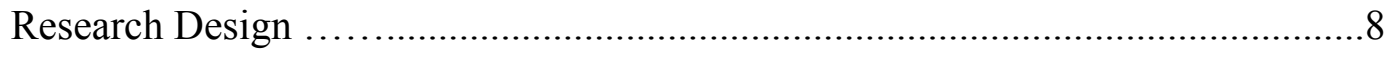

Instrumentation.........................................................

Competitive Anger and Aggressiveness Scale........................8

Moral Disengagement in Sport Scale..................................9

Demographics............................................10

Injury Analysis.............................................. 10

Procedure.............................................................. 11

Data Analysis........................................................ 12

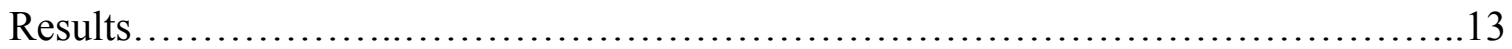

Discussion................................................................ 14

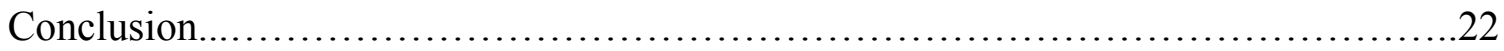

References.................................................................23

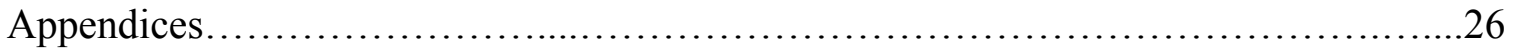

Appendix A: The Problem................................................27

Appendix B: Literature Review.......................................... 33

Appendix C: References...........................................80 


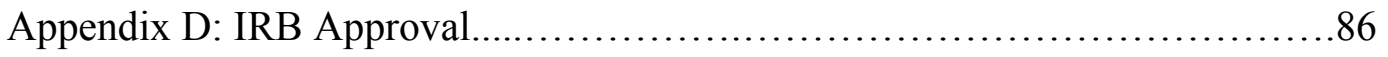

Appendix E: The Competitive Anger and Aggression Scale.......................88

Appendix F: The Moral Disengagement in Sport Scale.........................89

Appendix G: Demographic Questionnaire ..................................92

Appendix G: Cover Letter and Information Page.............................93 


\section{INTRODUCTION}

According to Murphy and Waddington ${ }^{1}$ sport injuries are very common when participating in athletics and, therefore, injury rates should be monitored. By tracking and critically analyzing the occurrence of injuries athletic trainers and other sports medicine professionals can institute preventative measures to ensure the safety of athletes. ${ }^{2}$ Thus, it should come as no surprise that the National Collegiate Athletic Association (NCAA) currently uses the Injury Surveillance System (ISS) to monitor injury trends in various sports. Since the inception of the ISS the NCAA has reported approximately 182,000 injuries. ${ }^{2}$ However, while the ISS has proven to be an effective method for reporting the incidence of injuries and the factors related with occurrence; the NCAA only documents the physical and environmental mechanisms of injury while omitting various other causes of injury. ${ }^{2,3}$ Various other causes such as psychological, social and emotional factors may also predispose an athlete to sustaining an injury and should also be investigated. ${ }^{3-5}$

Despite the aforementioned factors, research has shown that the innate characteristics that compose one's personality also influence the occurrence of athletic injury. ${ }^{4-7}$ According to the Anderson and Williams Stress-Injury Model, ${ }^{8}$ personality factors, either alone or in combination with an athlete's history of stressors and coping resources, influence the stress response. It is this response, according to the Anderson and Williams model ${ }^{8}$, that precedes the occurrence of an injury. Moreover, some research findings have suggested that the relationship between personality factors and injury occurrence could potentially serve as method to prevent injury. ${ }^{6,9}$ Some factors that have been implicated in the occurrence of injury and omitted by the ISS ${ }^{2}$, include the current mood state of the athlete, trait anxiety, and anger or hostility. ${ }^{9}$ 
Some research ${ }^{9}$ has been performed examining the relationship between injury and personality traits. Lavallee and Flint ${ }^{9}$ examined whether personality factors, such as stress and anxiety, the subject's current mood state and social support, in relation to the occurrence of injury in a sample of athletes. The goal of this study was to determine whether personality factors could be related to injury and severity. Results indicated that there was a relationship between the number of injuries recorded and competitive anxiety and trait tension/anxiety. Furthermore, it was shown that trait tension/anxiety and anger/hostility were related to the severity of the injury that the athlete sustained. ${ }^{9}$ It is finding such as this that indicate a potential relationship between personality factors and the occurrence of injury. As such, the authors of this study reported that these findings could be further utilized in the athletic training room setting to identify athletes more prone to sustaining an injury. ${ }^{9}$ Similarly, Fields and colleagues ${ }^{6}$ examined whether participants identified with having a Type A personality would be more likely to sustain an injury over the course of a year while being a member of a running club. ${ }^{6}$ While the findings were not significant, the participants with a Type A personality lost approximately double the amount of training time due to injuries sustained. ${ }^{6}$ These studies ${ }^{6,9}$ seem to indicate that traits such as anxiety can potentially predispose an athlete to sustaining an injury during sport participation.

One trait of particular interest that has been neglected within the literature is an athlete's level of aggressiveness. ${ }^{4}$ According to the literature ${ }^{6,8-10}$ personality can play a potential role in how an athlete will respond to a stressful situation during sport participation. Using this reasoning and the aforementioned studies ${ }^{6,9}$ it can be hypothesized, that an athlete with aggressive tendencies may also be at an increased risk 
for sustaining an injury during athletic participation. Moreover, the author of the current study believes that given the reported rates of aggressiveness in sports and its postulated effect on injury rates it should come as no surprise that there has been an increased emphasis by researchers in an attempt to determine the legitimacy of the actions within the specific context of athletics. ${ }^{11-15}$

Although aggressive behavior has been thoroughly documented in the literature a more specific innate personality factor, trait aggression, can potentially have a major influence on an athlete's behavior on the field or on the court. ${ }^{4,6,7}$ Trait aggression has been defined by researchers Buss and Perry ${ }^{16}$ as “... the inclination to engage in aggressive behavior, physical or verbal, hold hostile cognitions of others, and finally to express anger." ${ }^{(\mathrm{p} .452)}$ Moreover, trait aggression is believed to be stable throughout an individual's life span. ${ }^{16}$ Bushman and Wells ${ }^{17}$ have corroborated this assertion since it has been shown that as individuals age and mature their level of trait aggression remains constant. However, additional studies, ${ }^{13-15,18}$ have found that individuals with high levels of trait aggression are more likely to engage in behaviors that are considered to be aggressive.

While the relationship between injury rates and aggression has yet to be extensively examined, the literature seems to indicate a potential relationship between personality and sports related injuries. ${ }^{5,19,20}$ Junge $^{19}$ reported that while personality types might predispose athletes to sustaining injuries various traits that have been omitted from the research include: level of concentration, propensity toward anger, and aggression. Kimball and colleagues, ${ }^{4}$ further reported that the relationship between injury and aggressive behavior has been “...largely ignored...” (p. 7) Locke ${ }^{20}$ presented a similar 
argument and stated that the outcomes of aggressive behavior, such as incidents of injury, need to further examined.

Since injury prevention is one of the most important functions that can be provided by sports medicine professionals, investigating this relationship may identify those athletes at risk. Consequently, if athletes are found to have a high level of aggression that would potentially predispose them to sustaining injury, it may be possible to initiate an intervention plan to address these issues. Some research has been done in this area. ${ }^{4,5,7}$ More specifically, Thompson and Morris ${ }^{5}$ reported that a relationship exists between stressful life events, aggressiveness, attention, and injury in an athletic adolescent population. According to their findings ${ }^{5}$ it was shown that highly aggressive athletes and those athletes that display little to no aggressiveness are more predisposed to sustaining injury.

Emery and colleagues ${ }^{7}$ also examined the relationship between trait aggression and injury. Results indicated that there was not a relationship between trait aggression and number of injuries incurred over the course of a season. However, the authors did report that as levels of trait aggression increased the violent actions, which may result in injury, did as well. ${ }^{7}$ Additionally, Lavarda ${ }^{21}$ reported that injury proneness was related to impulsivity, aggression, and guilt. By determining a relationship between aggression and injury proneness, Lavarda ${ }^{21}$ further supported the possibility that aggressive individuals may be predisposed to sustaining an injury. However, as previously stated, the relationship between injury rates and trait aggression has not been specifically examined in the literature and therefore further investigation is needed. 
It is important to take a global approach when initiating these programs by examining numerous other factors that may also increase the level of aggression since there are multiple influences on one's actions. One such factor that should be examined is the athlete's level of moral reasoning and how aggressive actions are justified. Investigation of the relationship between moral reasoning and risk taking behaviors has shown that as the level of moral disengagement increased the behaviors become increasingly more questionable and dangerous. ${ }^{21-24}$

Moral disengagement was developed by Albert Bandura ${ }^{24}$ as a component of the social cognitive theory and is a self-regulatory procedure that involves the cognitive restructuring of conduct not accepted by society, the view of the recipients of the acts, or one's role in this transgression. ${ }^{23}$ According to Albert Bandura's social cognitive theory of the moral self, ${ }^{23,24}$ development occurs as rules are made that guide our moral conduct. When having to make a decision, an individual analyzes the positive and negative consequences of the action and based on the perceived result, a decision will be made. Bandura ${ }^{24}$ further stated that if people make just and moral decisions they will feel better about themselves and the behavior will continue. However, when the decision goes against the adopted moral code the result will be self-condemnation. ${ }^{24,25}$ The processes of Bandura's ${ }^{24}$ social cognitive theory are concrete and people can consciously override this process by disengaging themselves with the action and cognitively adjusting the situation to portray their decision as moral or just. ${ }^{24,25}$ This removal of the morality or selfcondemnation from the decision can occur when one utilizes any of the eight mechanisms of moral disengagement. ${ }^{23-25}$ 
It has been argued that behavior and the factors that can predispose one to actions are important aspects to examine since behavior directly influences our interactions and responses to others. ${ }^{26}$ This construct, of moral disengagement, has been readily examined in sport with some common themes. Moral disengagement has been found to be correlated with aggression in young athletes. ${ }^{22,23,27}$ In a critical review of the literature concerning moral behavior in sport it was reported that a strong inverse relationship exists between moral reasoning and aggressive behavior. ${ }^{25}$ Athletes who reported low moral reasoning were more likely to partake in immoral actions. ${ }^{22}$ Therefore, it could be argued that the processes of moral disengagement were occurring and enabling athletes to remove themselves from blame and consequently take part in aggressive actions. Boardley and Kavissanu ${ }^{26}$ have shown that those athletes who reported feelings of aggression being a legitimate tool for success in sport were more likely to report the use of aggression against opponents during competition utilizing the mechanisms of moral disengagement.

Moral disengagement in sport can potentially become a major issue for sports medicine professionals if athletes are repetitively acting aggressively with no moral regulation of their behavior and placing themselves and others at a risk for injury. These athletes may be placing not only themselves but also others at an increased risk for a sports related injury. This behavior pattern may continue to perpetuate and result in progressively worsening aggressive behavior and therefore increasing the risk for more serious injury. By examining the levels of moral disengagement in sport it may be possible to initiate intervention strategies prior to the occurrence of serious injury. It is 
important that the sports medicine team evaluates all possibilities of injury predisposition and therefore both the physical and personality influences should be accounted for.

When attempting to prevent injuries sports medicine professionals are typically trained to determine and correct issues that may predispose athletes to injuries. ${ }^{2}$ However, as shown by numerous researchers ${ }^{4,5,7,8,21}$ personality may potentially play a major role in the occurrence of injuries. One scenario that has yet to be extensively examined in the literature is the relationship between trait aggression and injury. Some studies ${ }^{5,7,21}$ have determined that a relationship does exist; however, the findings of these studies are equivocal. Therefore, further investigation is warranted in order to determine whether factors such as trait aggression plays a role in the occurrence of injury. If a relationship is determined to exist indicating that increased aggression levels do predispose an athlete to injury it may be the responsibility of the sports medicine professional in cohort with trained sport psychology professionals, to initiate intervention strategies that will serve to address the level of aggression and potentially decrease the risk of injury. By examining the level of moral disengagement and level of trait aggression the professionals working with the athletes may be able to prevent further incidents of injury from occurring. As a result the purpose of this investigation will be to examine if a relationship exists between (a) the level of trait aggression and number of injuries reported and (b) trait aggression and moral disengagement in sport. Based on the findings in previous literature, it has been hypothesized in the current study that those participants with high levels of aggressiveness will (1) have an increased number of reported injuries to the athletic training staff and (2) report a higher level of moral disengagement. 


\section{METHOD}

\section{Research Design}

The study utilized a descriptive correlational design to examine the relationship between the level of aggressiveness, reported injuries and moral disengagement. The independent variable in the current investigation was the score on the Competitive Aggressiveness and Anger Scale (CAAS) ${ }^{28}$ and the two dependent variables, reported number of injuries from the individual medical records and the scores on the Moral Disengagement in Sport Scale (MDSS). ${ }^{27}$ The dependant variable of moral disengagement was composed of six subscales on the Moral Disengagement in Sport Survey (MDSS). ${ }^{22-24,26,27}$ Participants were recruited for the study using a convenience sampling method.

Participants

The current study was composed of collegiate athletes $(N=116)$, both male $(n=$ $106)$ and female $(n=10)$, who participate in football $(n=73)$, men's basketball $(n=12)$, women's basketball $(n=5)$, men's soccer $(n=21)$, and women's soccer $(n=5)$ at a MidAtlantic, NCAA Division III university. Participants ranged in age from 18 to $26(M=$ $19.65, S D=1.33$ ). Athletes' reported injuries ranged from zero to four injuries over the course of a season $(M=1.02, S D=1.079)$.

Instrumentation

\section{Competitive Anger and Aggressiveness in Sport Scale. The Competitive Anger} and Aggressiveness in Sport Scale is a 12-item scale that was developed to quantify the levels of anger and aggressiveness in athletes participating in sport (CAAS ${ }^{28}$ : See Appendix E). The scale is composed of six items that measure aggressiveness and six that 
measure anger in the participants. For the purposes of the current study only the six aggressiveness items were used. An example of an item on the aggressiveness scale includes "I use excessive force to gain an advantage" while "I get mad when I lose points" is from the anger scale. ${ }^{28}$ The measure utilizes a 5-point Likert scale (1 "almost never" to 5 "almost always"). The score in each section is determined by adding up the total value of the responses to the items. The greater the total score the higher level of aggressiveness. ${ }^{28}$ The test-retest validity was determined to be 0.88 for the whole measure, 0.84 for the aggression subscale, and finally 0.86 the anger subscale, which were considered to be acceptable results. ${ }^{28}$ The authors of the study reported the Moral Disengagement in Sport Questionnaire. The Moral Disengagement in Sport Scale ${ }^{27}$ is a 32 -item scale designed to assess the levels of the eight mechanisms of moral disengagement: moral justification, euphemistic labeling, advantageous comparison, displacement of responsibility, diffusion of responsibility, distortion of consequences, dehumanization and attribution of blame (MDSS ${ }^{27}$ : See Appendix F). ${ }^{27}$ The MDSS was specifically designed to evaluate Bandura's theory within in the context of sporting events. ${ }^{27}$

The MDSS is composed of six subscales to measure the eight mechanisms of moral disengagment. ${ }^{27}$ The MDSS originally had eight subscales; however, following the statistical analysis of the measure the authors ${ }^{27}$ determined that the mechanism of moral justification and euphemistic labeling as well as diffusion and displacement of responsibility were extremely similar. Thus, the authors opted for a six scale measure by creating conduct reconstrusal and non-responsibility. Conduct reconstrusal is an eightitem subscale which is composed of the mechanisms of moral justification and 
euphemistic labeling. Non-responsibility, is another eight item scale, which was created by combining the scales to measure diffusion and displacement of responsibility. ${ }^{27}$ The remaining mechanisms: advantageous comparison, distortion of consequences, dehumanization, and attribution of blame, are all single mechanism scales with four prompts on each scale. ${ }^{27}$ Respondents are asked to rate their agreement with each statement using a 7-point Likert scale ranging from 1 "I strongly disagree" to 7 "I strongly agree". ${ }^{28}$ To score the scale the investigator will determine the sum total of the responses in each section with higher scores indicating higher levels of moral disengagement. The maximum score that can be attained the subscales of advantageous comparison, distortion of consequences, dehumanization, and attribution of blame is a 28 with a minimum score of 4 . Non-responsibility and construct reconstrusal, which are composed of eight items have a maximum score of 56 and a minimum of $8 .^{27}$

The convergent validity of the measure was determined by comparing the correlation between the MDSS and a measure of societal moral disengagement. ${ }^{27}$ Boardley and Kavussanu ${ }^{27}$ reported that their measure had moderate level of correlation to the scale of societal moral disengagement $(r=0.71, p<0.01)$. The concurrent validity was measured using the MDSS compared to a measure of antisocial and prosocial behavior. Boardley and Kavussanu's ${ }^{27}$ data showed the expected findings were supported since a positive relationship was found between moral disengagement on the MDSS and a scale that measures antisocial behavior $(r=0.60, p<0.01) .{ }^{27}$ An inverse relationship was determined to exist between prosocial behavior and moral disengagement on the same scale $(r=-0.31, \mathrm{p}<0.01)$. The authors of the MDSS 
reported that internal consistencies of the eight subscales range from 0.73 to 0.95 , which indicated acceptable to very good levels of reliability. ${ }^{27}$

Demographic Information. The descriptive information of the athlete collected included: participants ages, gender, year in school, and sport affiliation. Additionally participants provided the number of injuries they reported to the certified athletic trainer during either practice or game. The participants also indicated whether they sustained an injury which prevented them from completing the season. (See Appendix G).

Injury Analysis. Participants' medical records and team injury reports were examined to determine the number of reported injuries during the season. Only musculoskeletal injuries were included for data analysis. All general medical conditions, such as illnesses, or those injuries not sustained during athletic participation were omitted from the data analysis. The head athletic trainer for football utilized a team injury report, which is a comprehensive list of all the team's injuries. The reports were prepared each day prior to the teams' practice and then filed. Every football injury reported to the athletic trainers with football has been recorded on this report. For the remaining sports (men's and women's soccer, men's and women's basketball, and wrestling) injury documentation was retrieved from athletes' medical file.

Procedure

The coaches of the teams included in the study were contacted and informed of the goals of the study and asked if they would be willing to allow their team to participate. Once the coaches agreed to allow their athletes to enroll in the study a meeting with the athletes was arranged and occurred prior to or at the conclusion of practice or team lift. Since the study involved human participants the Institutional Review 
Board for the Protection of Human Services (IRB) approval was obtained prior to the beginning of the data collection. During this meeting the study was fully described and the athletes were invited to participate. Prior to the distribution of the questionnaires any questions or concerns were addressed. The subjects were informed that their participation was entirely voluntary and they could have withdrawn themselves from the study at any time. Furthermore they received no incentives for being a part of the study. Once this was completed the participating athletes were given a packet containing a cover letter and information page (See Appendix H), demographic information (See Appendix G), the CAAS (See Appendix E), and the MDSS (See Appendix F).

Participants were assigned an identification number so that their personal information would remain confidential. The data obtained from the self-reported measures was then entered onto a spreadsheet in the Predictive Analytic Software (PASW/SPSS) statistical analysis software using the athlete's identification number. The medical files and injury reports were obtained and the relevant injuries were counted and recorded.

\section{Data Analysis}

Descriptive statistics including means and standard deviation were calculated and reported for the demographic information. The Pearson product-moment correlation was the main statistic used to examine the relationships between trait aggression and reported injury and moral disengagement. The data was examined using SPSS Version 18 (IBM Corporation, Somers NY). If a correlation was determined to be equal to or greater than $0.80(p \geq 0.80)$ the relationship was described as a positive strong correlation, between 0.50 and $0.79(0.50 \leq p \leq 0.79)$ was a positive moderate correlation, and finally less than 
less than $0.49(p \leq 0.49)$ was a weak relationship. Finally, the significance level was 0.05 for a statistical finding to be considered significant $(p \leq 0.05)$.

\section{RESULTS}

Demographic Information

The sample was composed of participants from all academic standing: freshman $(n=50)$, sophomore $(n=25)$, junior $(n=29)$, and senior $(n=9)$. The athletes reported a total of 118 injuries to the athletic training staff $(M=1.02 ; S D=1.079)$. From the total sample, $39.7 \%(n=46)$ athletes reported no injuries, $33.6 \%(n=39)$ reported one injury, $14.7 \%(n=17)$ reported two injuries, $9.5 \%(n=11)$ had three reported injuries, and finally $2.6 \%(n=3)$ had 4 injuries. There were a total of 18 athletes who reported sustaining a season ending injury. Instrumentation

The mean score on the CAAS was calculated for the entire sample $(M=14.13$, $S D=5.653)$ as well as for males $(M=14.56, S D=5.675)$ and females $(M=9.60, S D=$ 2.757). The means and standard deviations of subscales on the MDSS were calculate as well: conduct reconstrusal $(M=27.68, S D=10.08)$, advantageous comparison $(M=$ $14.91, S D=6.37$, non-responsibility $(M=21.87, S D=9.29)$, distortion of consequences $(M=13.13, S D=6.92)$, dehumanization $(M=12.94, S D=6.74)$, and finally attribution of blame $(M=12.78, S D=5.77)$.

\section{Relationship Between Trait Aggression and Reported Injuries}

Findings revealed that a weak but significant positive correlation existed between scores on the CAAS aggressiveness scale and the number of injuries reported to the certified athletic trainers during the season $(r=0.216 ; p=0.02)$. 


\section{Relationship Between Trait Aggression and Moral Disengagement}

The correlations between the scores on the CAAS and MDSS were all found to be significant and positively correlated. More specifically, Conduct Reconstrual $(r=0.598$; $p<0.001)$, Advantageous Comparison $(r=0.481 ; p<0.001)$, Non-responsibility, $(r=$ $0.448 ; p<0.001)$, Distortion of Consequences $(r=0.516 ; p<0.001)$, Dehumanization $(r$ $=0.558 ; p<0.001)$, and finally Attribution of Blame $(r=0.407, p<0.001)$. Therefore, the relationships between aggressiveness and advantageous comparison, nonresponsibility, and attribution of blame were considered to be positive but weak; while, the relationship between the distortion of consequences, dehumanization, and conduct reconstrual are positive moderate correlations.

\section{DISCUSSION}

According to the literature ${ }^{4,19}$ aggression appears to be one of the personality factors which is potentially related to injury occurrence. However there appears to be a void in the literature; thus, a further investigation into this relationship seemed warranted. Consequently, the aim of the current study was to examine the relationship between trait aggression and the number of reported injuries that occurred over the course of a season. According to the results it was shown that a relationship does in fact, exist between the levels of aggressiveness and the number of reported injuries. Additionally, the six subscales on the MDSS, measuring the eight mechanism of moral disengagement, were found to be positively correlated with the level of aggressiveness in the sample population.

The current study revealed that a positive but weak correlation existed between aggressiveness and injury rates in the sample collegiate population. This finding appears 
to be very similar to the results reported by Lavarda ${ }^{21}$ and Thompson and Morris. ${ }^{5}$ According to Lavarda ${ }^{21}$ a sample of elite athletes involved in a variety of sports were more likely to sustain an injury if shown to act aggressively. Thompson and Morris ${ }^{5}$ also found that two groups of athletes were more at risk for injury: those that were minimally aggressive and the ones that were highly aggressive. From the results of the current study it can be inferred that those athletes reporting high levels of aggression were more likely to sustain an injury as shown by Thompson and Morris. ${ }^{5}$ However, some major differences between the current study and the aforementioned research ${ }^{5}$ may have accounted for the differences in findings. Among these were the questionnaire used, the age groups utilized, and finally the method of injury collection. In Thompson and Morris' ${ }^{5}$ research the sample was obtained from a group of local high school football players with ages ranging from 14 to 18 years which were younger than the sample used in the current study. Secondly, the authors utilized weekly interviews with coaches and athletic trainers to obtain injury information whereas in the current study the medical files were examined for the necessary data. However, the findings were similar and therefore it may be assumed that these differences did not significantly affect the outcome of the determined results.

Finally, the findings of the current study were a stark contrast to those of Emery and colleagues ${ }^{7}$ which found that no relationship existed between the aggression level of the athletes and the number of injuries sustained across a hockey season. Again, there were major differences in the current study and the study performed by Emery and colleagues ${ }^{7}$ such as the age of the participants, the sports that were examined, and the method of data collection. As in the study performed by Thompson and Morris ${ }^{5}$ the 
sample examined by Emery and colleagues ${ }^{7}$ were younger than the current research's population with an age range of 11 to 16 years old. Furthermore, the method of injury data collection occurred bi-weekly with an interview. The population that was utilized by Emery and colleagues ${ }^{7}$ only included those athletes that were participating in a youth hockey league; while the current study examined a population composed of participants involved in various sports at the collegiate level.

Thus far, there has been no research identified that examined the relationship between moral disengagement and aggressiveness; however, it has been shown that the participants that display high levels of moral disengagement are more likely to act aggressively in setting other than sport. ${ }^{22,23}$ Moral reasoning and sport has been examined by Long and colleagues ${ }^{22}$ and by Corrion and others. ${ }^{23}$ The study performed by Long and colleagues ${ }^{22}$ found that moral reasoning played a major role in actions of athletes during sport participation. The findings of the study showed that the athletes displayed the signs of moral disengagement during sports. In a study by Corrion and colleagues ${ }^{23}$ it was reported that the mechanisms of moral disengagement were highly employed during athletic participation which can be seen in the data of the collected study. The authors ${ }^{23}$ reported that the mechanisms of moral disengagement allowed the athlete to engage in activities that are not allowed during sport participation.

The findings of the current study indicated that aggressiveness and injury rates were positively correlated. Moreover, based on the results, the author can assume that as an athlete's level of aggressiveness increased the number of injuries reported did as well. There are numerous potential reasons why this relationship may be present. First it could be assumed that as the level aggressiveness of an athlete increase he or she will find an 
outlet during sport that will allow them to behave in such a manner. Moreover, given the sports included in the study, these aggressive behaviors may potentially place both the intended target and the perpetrator at an increased risk for injury. For example, in soccer if an athlete is attempting to slide tackle a player on the opposing team there is a chance he or she may sustain an injury while sliding. It is likely that the personality traits that influence a person's responses may guide the behavior that the athlete displays during sport.

Various theories have been presented to describe aggressiveness in sport; this, in conjunction with the findings of the current study may help to further illustrate the relationship between aggressiveness and injury in sport. The first theory, the FrustrationAggression Theory, presented by Berkowitz,${ }^{30}$ and states that when an athlete is unable to achieve a specific goal that he or she is aiming for, such as scoring a goal, or winning a competition, frustration will result. It is these feelings of frustration that results in an emotional response which can be vented with aggressive actions. ${ }^{15}$ Therefore it may be that as the athlete is unable to achieve a certain aim the likelihood of aggressive behavior could increase and result in injury.

The second theory that has been presented in the literature is Bandura's ${ }^{25}$ social learning theory; which states that individuals learn how to respond in given situations by observing the response of others in similar scenarios. Thus, if an individual sees another athlete acting aggressively during sport participation he or she may be more inclined to respond similarly. ${ }^{15}$ Freshmen $(n=50)$ and sophomores $(n=25)$ may model their behaviors during sport participation on the actions of the upperclassmen, juniors $(n=29)$, and seniors $(n=9)$; thus, allowing social learning to occur. If one of the older classmen 
are displaying high levels of aggressiveness with positive outcomes and reinforcement from the coaches and staff the underclassmen may begin to follow the example and act in a similar fashion. Therefore, according to the current findings if an individual is learning to express his or her aggressive tendencies during sport participation the possibility may increase as a result of these behaviors.

Since it has been theorized ${ }^{19}$ that aggressiveness may predispose an individual to participate in potentially violent actions it seems likely that moral reasoning may also influence the athlete to further engage in such behavior. Since violent actions in sport are typically against the rules the athlete may engage the mechanisms of moral disengagement in order to feel that the actions are justified. Therefore, if an athlete is likely prone to acting aggressively and committing fouls in the sport he or she participates in the innate moral regulators within the self needs to be overridden which would require the use of one or more mechanisms of moral disengagement. This premise shows that the more aggressive an athlete is the more likely the need for the mechanisms of moral disengagement become as revealed by the findings of the current study. However, this has been theorized from the findings of the current study and further research is needed to substantiate these results.

The findings of the current study may be useful to athletic trainers and the sport psychologists as an additional method of injury prevention. By identifying those athletes who may be highly aggressive it may be possible to utilize some form of intervention to prevent these tendencies. By attempting to initiate an intervention once the athlete has been identified the sports medicine department may be able to protect the athlete from sustaining an injury during athletic participation. If an athlete is constantly reporting 
injuries during sport participation it may be that he or she is displaying aggressive behavior during sport participation and therefore placing themselves at a higher risk for sustaining an injury. Thus, it becomes the athletic trainer's responsibility to attempt to prevent further injury from occurring; however, if it is that the athlete is acting too aggressively during sport it may be necessary to refer the athlete to a mental health professional. According to Kimble ${ }^{4}$ there has been one study performed ${ }^{29}$ that examined the showed an improvement in the athlete's behavior through use of an intervention.

The study performed by Brunelle and colleagues ${ }^{29}$ was identified to be one of the only studies available examining the effectiveness of an intervention on aggressiveness and angry behavior in sport. The research randomly placed a sample of male athletes into one of three groups: (1) role playing, (2) anger awareness group, or (3) the control group. ${ }^{29}$ The role playing intervention was composed of one hour meetings across a five week time period. The participants began the technique by attending an educational lecture about the effects of competitive anger as well viewing live demonstrations and alternative responses. For the remainder of the sessions the athletes would take turns observing and taking part in scenarios designed to test whether they could react in an unaggressive manner. ${ }^{29}$ The anger awareness group met for five weeks by attending one hour sessions which involved discussions on the topics of specific incidents of anger and aggressive behavior. The athletes were also required to monitor their angry feelings and behaviors that were reported and followed by group discussions. ${ }^{29}$ The findings indicated that none of the interventions could reduce the angry feelings that arose during sport; however, the role playing and anger awareness interventions both could effectively reduce aggressive behaviors during sport participation. It was theorized that this finding 
is likely to have occurred due to the athlete being more aware of his behaviors during sport. ${ }^{29}$ If an athlete is determined to display high levels of aggressive behavior, whether it be determined though observation of practices or games, records of penalties or fouls, through personal interaction or the reports of other team members he or she may enlisted in a program, as previously described, ${ }^{29}$ which may serve to reduce these behaviors. The findings of Brunelle and colleagues ${ }^{29}$ showed that there maybe some forms of intervention that may reduce aggressive behaviors.

Corrion and colleagues ${ }^{29}$ have offered some recommendations on how to effectively alter use of moral disengagement during sport participation. One method that may reduce the use of the mechanisms of moral disengagement in sport involved educating the athlete on self-regulatory skills as well as avoiding the social influences from coaches and teammates that may be pressuring the perpetration of the behaviors. ${ }^{29}$ This training would emphasize that the athletes assume responsibility for their actions during sport participation; thus, it is believed by being held accountable for their behaviors they may recognize the responsibility of the transgressions. The authors ${ }^{29}$ have stated that the use of debriefing sessions following sport competitions may be used to evaluation the athlete's performance as well as identify specific situations for discussion. However, the authors ${ }^{29}$ have acknowledged that further research is necessary on this topic.

There were some limitations that were encountered during the current study which may have strongly influenced the outcome of the data collection as well as prevented these results from being generalized to the greater athletic population. First, a small sample was included in the study. Since the data collection was performed during 
the non-traditional spring season practices which are not typically attended by the upperclassmen which decreased the total sample size. The time of the data collection, the spring season, may have also influenced the responses of the participants. The psychological state of the athlete may be different during the non-traditional spring season since the practices are typically easier as compared to those that occur during the sport's season. The mindset of the athletes may fluctuate as a result of the time of the year possibly making them less aggressive when their respective sport is out of season. An additional limitation could have been the documentation of injuries by the athletic training staff on the athlete's behalf. The minor injuries sustained during practice and games that do not prevent the athlete from participating may not have been documented within an individual's medical files. Therefore, these injuries that may have been omitted could potentially have affected the findings of the current study. Finally, the total sample population was from a single division III University that has a significant religious affiliation which may have influenced the responses of the participations. The level of competition may have influenced the results of the current study. The athletes are from a Division III university which could influence the level of aggressiveness displayed due to the intensity of the competition.

With the aforementioned limitations, the author suggests that future research utilize a different method of injury collection. One possible method has been used by Emery and colleagues, ${ }^{7}$ an injury journal, which the athletes would complete themselves and be verified for accuracy by an athletic trainer. Furthermore, the time of data collection could be changed to ensure that the entire roster is present for the distribution of the questionnaires. By having the data collection during the formal sport season the 
number of participants will potentially increase the sample size. In an effort to improve the current study it could be recommended that multiple data collections occur, such as during the preseason, at the midpoint, and then at the conclusion of the season, to determine whether the level of aggressiveness changed based on the sport's demands. Finally, a fouth recommendation would be to include athletes from different colleges including those that are and are not religiously affiliated as well as at higher levels of collegiate competition, DI or DII schools.

\section{CONCLUSION}

The findings of the current study may allow for some insight into a potential predisposing factor of injury that may be amendable in the sports medicine setting. ${ }^{29}$ The findings of the current study indicate that a relationship exists between the number of injuries reported and aggressiveness in a sample of collegiate athletes. These results demonstrate that personality may act as a potential predisposing factor to sustaining an injury during athletics. Therefore, based on this finding it can be reasoned that more aggressive athletes are more likely to sustain and report injuries. A secondary purpose of this investigation was to determine if a relationship existed between the level of aggressiveness and moral disengagement in sport. This finding showed that the more aggressive athletes are the more likely they are to use the mechanisms of moral disengagement to justify the actions that may be considered to be morally reprehensible. However, there were no studies that were found examining intervention strategies to decrease the use of moral disengagement in the sporting context. It could the theorized that if the use of aggressiveness during sport is reduced through methods such as role playing and educational discussions there will be less of a need to morally justify one's 
actions and thus the need for moral disengagement may be absolved; further research is recommended to substantiate this theory.

These findings may benefit the sports psychology and sports medicine professionals as it may allow these professions to identify those athletes that are predisposed to sustaining an injury during competition due to their behaviors. With this data it can be seen that those athletes that are found to be highly aggressive are more likely to sustain an injury during participation. Therefore if a member of the sports medicine department has identified, through observation or interactions with others, that athlete is excessively aggressive during practices and games it may be necessary to intervene as a method of injury prevention for not only the specific athlete but others as well. The current data supports the idea that prevention of aggressiveness may also prevent injuries sustained during sports participation; it stands to reason that if the aggression can be decreased through numerous interventions ${ }^{29}$ the occurrence of injury may reduce as well. Although not examined in the current research, by addressing the level of aggressiveness in athletes the number of injuries sustained by others as a result of the behaviors may be reduced as well. If an athlete is acting violently during games and practice he or she is increasing the likelihood that an injury to another person may occur. By addressing the athlete's aggressiveness through role playing or anger awareness training ${ }^{29}$ the number of injuries may decrease benefitting both the athlete and the sports medicine team. 


\section{REFERENCES}

1. Murphy P, Waddington I. Sport for all: Some public health policy issues and problems. Critical Public Health. 1998;8(3):193-205.

2. Hootman JM, Dick R, Agel J. Epidemiology of collegiate injuries for 15 sports: Summary and recommendations for injury prevention initiatives. J Athl Training. 2007;42(2):311-19.

3. Emery CA, Meeuwisse WH. Injury rates, risk factor, and mechanisms of injury in minor hockey. Am J Sports Med. 2006;34:1960-69.

4. Kimble NB, Russo SA, Bergman BG, Galindo VH. Revealing an empirical understanding of aggression and violent behavior in athletics. Aggress Violent Beh. 2010.

5. Thompson NJ, Morris RD. Predicting injury risk in adolescent football players: The importance of psychological variables. J Pediatr Psychol. 1994;19(4):415-29.

6. Fields KB, Delaney M, Hinkle JS. A prospective study of type a behavior and running injuries. J Fam Pract. 1990;30:425-429.

7. Emery CA, McKay CD, Campbell TS, Peters AN. Examining attitudes toward body checking, levels of emotional empathy, and levels of aggression in body checking and non-body checking youth hockey leagues. Clin J Sports Med. 2009;19(3):207-15.

8. Williams JM, Andersen MB. Psychosocial antecedents of sport injury: Review and critique of the stress injury model. J Appl Sport Psychol. 1998;10(1):5-25.

9. Lavallee L, Flint F. The relationship of stress, competitive anxiety, mood state, and social support to athletic injury. J Athl Train. 1996;31(4):296-99.

10. Chantal Y, Robin P, Vernat JP, Bernache-Assollant I. Motivation, sportspersonship, and athletic aggression: A meditational analysis. J Sport Exercise Psy. 2005;6:233-249.

11. Pappas NT, McKenry PC, Skilken-Catlett B. Athlete aggression on the rink and off the ice. Men and Masculinities. 2004;6(3):291-321.

12. Rascle O, Traclet A, Souchon N, Coulomb-Cabagno G, Petrucci C. Aggressorvictim dissent in the perceived legitimacy of aggression in soccer: The moderating role of situational background. Res Q Exercise Sport. 2010;81(3):34048. 
13. Maxwell JP, Visek AJ. Unsanctioned aggression in rugby union: Relationships among aggressiveness, anger, athletic identity, and professionalization. Aggressive Behav. 2009;35:237-43.

14. Maxwell JP, Visek AJ, Moores E. Anger and perceived legitimacy of aggression in male hong kong Chinese athletes: Effects of type of sport and level of competition. Psychology of Sport and Exercise. 2009;10:289-96.

15. Gee CJ, Leith LM. Aggressive behavior in professional ice hockey: A crosscultural comparison of north American and European born NHL players. Psychology of Sport and Exercise. 2007;8:567-83.

16. Buss AH \& Perry M. The aggression questionnaire. J Pers Soc Psychol. 1992;63(3):452-459.

17. Bushman BJ, Wells GL. Trait aggressiveness and hockey penalties: Predicting hot tempers on the ice. J Appl Psychol. 1998;83(6):969-74.

18. Anestis MD, Anestis JC, Selby EA, Joiner TE. Anger rumination across forms of aggression. Pers Indiv Differ. 2009;46:192-6.

19. Junge A. The influence of psychological factors on sports injuries: Review of the literature. Am J Sports Med. 2000;28:S-10-5.

20. Locke KD. Aggression, narcissism, self-esteem, and the attribution of desirable and humanizing traits to self versus others. J Res Pers. 2009;43:99-102.

21. Lavarda A. Contributo allo studio della dendenza psicologica agli infortuni nello sport. Int J Sport Psychol. 1975;6:215-218.

22. Long T, Pataléon N, Bruant G, d'Arripe-Longueville F. A qualitative study of moral reasoning of young elite athletes. Sport Psychol. 2006;20:330-47.

23. Corrion K, Long T, Smith AL, d'Arripe-Longueville F. 'It's not my fault; it's not serious": Athlete accounts of moral disengagement in competitive sport. Sport Psychol. 2009;23:388-404.

24. Bandura A. Selective moral disengagement in the exercise of moral agency. $J$ Moral Educ. 2002;31(2):101-19.

25. Kavussanu M. Moral behaviour in sport: a critical review of the literature. International Review of Sport and Exercise Psychology. 2008;1(2):124-38.

26. Boardley ID, Kavussanu M. The influence of social variables and moral disengagement on prosocial and antisocial behaviours in field hockey and netball. J Sport Sci. 2009;27(8):843-54. 
27. Boardley ID, Kavussanu M. Development and validation of the moral disengagement in sport scale. J Sport Exercise Psy. 2007;29:608-28.

28. Maxwell JP, Moores E. The development of a short scale measuring aggressiveness and anger in competitive athletes. Psychology of Sport and Exercise. 2007;8:179-93.

29. Brunelle JP, Janelle CM, Tennant LK. Controlling competitive anger among male soccer players.

30. Berkowitz L. Frustration-aggression hypothesis: Examination and reformulation. Psychol Bull. 1989;106(1):59-73 


\section{APPENDIX A}

\section{THE PROBLEM}

\section{Research Question}

According to the NCAA Injury Surveillance System (ISS), in sixteen years of data, there have been 182,000 injuries reported to athletes during participation. ${ }^{2}$ With the high incidence of injury during participation there is a requirement for injury prevention. Therefore, the NCAA designed the ISS to track and report on the occurrence of injuries in sport. The goal of the ISS is to examine injury data such as trends to identify potential predisposing factors of injury during sports. ${ }^{2}$ However, the information reported includes only physical factors while research has shown that psychological influences can play a major role in predisposing athletes to injury. ${ }^{18}$ Various psychological factors, including ego orientation, experiencing stressful life events, and anxiety ${ }^{18,31}$, have been examined as possible causes of injury however, one factor that has been greatly ignored in the literature on psychology and injury is an athlete's innate aggressive personality.

There is limited information on the possible relationship that may exist between personality and injury. It has been shown that certain psychological influences, including trait aggression, may create a situation that results in more risk taking behavior in injured athletes. ${ }^{4}$ It is these risk-taking behaviors that could potentially lead to injury due to reckless behaviors. Another factor, which may be influenced by the innate level of trait aggression that has also been examined in sport, is the level or moral disengagement. This process allows athlete to remove morality from their actions on the field possibly increasing the risk of injury. ${ }^{25}$ If an athlete's aggressive behavior is not regulated by morality there is a chance that they are acting the previously mentioned risky behavior 
and thus at risk for serious injury. Therefore, it is evident why these constructs need to be further examined in relation to athletes and sports participation. As a result the purpose of this study will be to examine whether level of trait aggression is related to the number of injuries reported to athletic trainers and to the level of moral disengagement. Is there a relationship between levels of trait aggression to the number of injuries reported to certified athletic trainers? Is the level of moral disengagement related to the athlete's trait aggression?

Experimental Hypotheses

1. Athletes with higher scores on the CAAS indicating higher of trait aggression will have a greater number of injuries reported to the certified athletic trainers.

2. Athletes with higher scores on the CAAS indicating higher of trait aggression will also receive higher scores on the MDSS and therefore display higher levels moral disengagement meaning a positive correlation between trait aggression and moral disengagement.

\section{Assumptions}

1. Participants will complete the surveys as accurately and truthfully as possible.

2. The measures used have been shown to accurately assess the variables in the study and have acceptable levels of validity and reliability.

3. The certified athletic trainers that are assigned to the sports included in study have accurately documented the injuries over the course of the sport's respective season. 


\section{Operational Definitions}

1. Aggression: Any action that is performed with the primary goal of injuring or harming the recipient. The perpetrator must believe that the action will result in injury and that the recipient is likely to try and avoid. Displays of aggression may include physical or verbal actions. ${ }^{28,32}$

2. Trait Aggression: An innate factor in one's personality that inclines one to act aggressively by displays of physical or verbal aggression, have hostile ideas, or express anger toward the recipient of the action. ${ }^{16,28}$

3. Athletic Injury: Any musculoskeletal injury, including concussion that occurred during either practice or competition that was reported to and documented by the certified athletic trainer(s) covering the respective sport.

4. General Medical Condition: Any medical disease, illness, or musculoskeletal injury that can be attributed to a viral or bacterial cause, or that occurred in another setting not related to athletic participation.

5. Moral Disengagement: Moral disengagement acts to reduce the inhibitive actions of morality, on the conscience, which acts as a moderator between performing reprehensible actions and self-reactions that serve to regulate human behavior. The process is composed of eight mechanisms by which people can cognitively disassociate themselves from the unmoral action. ${ }^{23,24,27}$

6. Moral Justification: The cognitive reconstruction of a blameworthy action into one that would be considered morally or socially important and therefore justifiable and acceptable. ${ }^{23,24,27}$ 
7. Euphemistic Labeling: Using selective language that modifies one's perception of the harmful behaviors into one that is less culpable. ${ }^{23,24,27}$

8. Advantageous Comparison: Occurs when a transgression that would be considered to be far worse is compared to the original action. The first transgression appears to be less reprehensible when compared. ${ }^{23,24,27}$

9. Displacement of Responsibility: People will attribute their behaviors to pressures or instructions from others and therefore they cannot be at blame for their actions. $^{23,24,27}$

10. Diffusion of Responsibility: Occurs when the labor of a transgression is divided amongst a party or a whole group makes a decision the outcome of the deed becomes attributable to all people rather than one. ${ }^{23,24,27}$

11. Distortion of Consequences: By minimizing or refusing to accept the results of the wrongdoing having to accept the responsibility of the outcome appears to be less severe and the likelihood for self-regulation of behavior can avoided. ${ }^{23,24,27}$

12. Dehumanization: By removing the humanlike qualities of the recipient of the actions and cognitively attributing animalistic traits to the individual. This mechanism allows the perpetrator to transgress against someone less than human. ${ }^{23,24,27}$

13. Attribution of Blame: The infraction is considered to be retaliation for a previous incident and therefore morally acceptable because the action is making the situation right. ${ }^{23,24,27}$ 


\section{Limitations}

1. Since the participants of the study are from a small Christian Mid-Atlantic Division III University, their responses may be influenced by their religious education and upbringings and thus the results cannot be generalized beyond this setting.

2. The only women's sports that are included in the study, basketball and soccer, therefore, the current study will consist of mostly males, thus limiting the application of the results to the female population.

3. Participants may respond to the self-report measures in a socially desirable manner.

4. The reported injuries will be based on the medical records of the athlete and therefore is dependent on the certified athletic trainer accurately reporting and documenting injuries.

Significance of the Study

Sports medicine professionals are constantly attempting to identify predisposing factors to injury in order to protect the wellbeing of their athletes. Consequentially, there has been extensive research into prevention of injuries that occur as a result of external or internal influences. One factor that has been readily examined as a potential cause of injury is the athlete's personality. ${ }^{7}$ Even this research has not been exhaustively performed with major variables still relatively unresearched. ${ }^{18}$ One such example of a factor that has not been examined in depth in the literature is trait aggression. ${ }^{4,6,18 .}$ The purpose of this study is to examine whether the athlete's innate level of trait aggression is related to the number of injuries reported to athletic trainers by those athletes 
participating in a high contact sport over the course of a season. By determining those athletes with high trait aggressiveness sports medicine professionals may be able to predict whether there is an increased chance for injury during athletic participation. Therefore, knowledge of the relationship of aggression and injury may allow for referral to the appropriate health professional. In addition injury rates and the relationship to trait aggression the moral disengagement will also be examined.

The performance of an aggressive action is as important as the justification behind it; therefore, this study will also examine the relationship between moral disengagement and trait aggression. Studies have shown that higher levels of moral disengagement have been linked to aggressive behavior in sports. ${ }^{23}$ Therefore examining the reasoning behind the action may allow for some prevention methods to be enacted prior to the beginning of the athlete's season. By attempting to alter the cognitive functions of the athletes in sports that require significant amounts of physical contact the number of injuries may be reduced. 


\section{APPENDIX B}

\section{LITERATURE REVIEW}

\section{AGGRESSION}

Aggression has become a major issue in sport and as a result been the subject of

extensive research. ${ }^{33}$ However, various definitions of aggression have been presented in the literature depending on the context of research. The most common definitions in the literature essentially define aggression as any form of action with the direct goal of incurring harming or injuring another person while the recipient is motivated to avoid such treatment. ${ }^{13,32,33}$ This definition serves to ensure that accidental incidents are not considered to be aggressive since there was no intention to harm the individual. ${ }^{32}$ The International Society of Sports Psychology’s definition of aggression includes verbal, physical, or gestural aggression between people in addition to mentioning that aggression is not an attitude but a behavior and is performed with the intent to injure. ${ }^{14}$ Using the various definitions it is clear that aggression is not just manifested as a physical action but can be expressed in a variety of different ways. ${ }^{13,32,33}$ Including all methods of portraying aggression can greatly enhance one's investigation of the topic in relation to sports since athletes may express their aggression through any channel. Once the concept of aggression is understood it is important to understand what factors can influence the expression of the behaviors. Aggression in sport can have a number of predisposing factors including one's innate personality or level of trait aggression.

Trait aggressiveness is one of the most important measures when examining aggression in any context and is defined, as the personality trait of being aggressive. ${ }^{15}$ By utilizing a measure that assesses an athlete's level of inherent aggression researchers may 
be able to predict those participants that are likely to respond in a similar manner. Archer and Webb ${ }^{34}$ have reported that scores on the Buss and Perry Aggression Questionnaire could predict, in a sample of collegiate males, incidents of violence and aggressive actions. The authors ${ }^{34}$ also showed that past events of reported violence could be strongly predicted by those participants reporting high levels of trait aggression indicating a relationship between the variables. This factor, of trait aggression, is ingrained into an individual's personality and according to the literature is relatively consistent throughout the lifespan. ${ }^{17}$ The consistency across one's life is interesting since regardless of the measure used to examine trait aggression the results remain stable ${ }^{17}$ Therefore, those athletes with high levels of trait aggression are more likely to be aggressive throughout the lifespan and be more apt to engage in violent or confrontational behaviors. Since trait aggression has been shown to be constant throughout the lifespan it seems to reason that this behavior should be seen in all activities that people would participate in.

Instances of aggression in daily life and in sport are similar with respect to trait aggression. High levels of trait aggression were one of the strongest predictors of aggressive actions in sport. ${ }^{13}$ In sport there are two types of aggression that are discussed in the literature: sanctioned and unsanctioned aggression. ${ }^{12}$ Any aggressive behavior or action that does not violate any rules of the sport is termed sanctioned aggression. ${ }^{12,13}$ Conversely, unsanctioned aggression is any type of aggression that is not permitted within a sport. Intent plays an extremely important role in aggression and should be examined as closely as the type of aggression. ${ }^{12,13}$ There are three types of motivational aggression including instrumental, reactive, and hostile; these essentially describe the athlete's reasoning behind committing the act. ${ }^{13}$ Instrumental aggression occurs when 
someone transgresses against opponents to secure a positive game outcome. ${ }^{13}$ Reactive aggression involves an athlete's anger and aggression as an instant reaction to some provocation. And finally, hostile aggression is a planned transgression that may occur some time after the original incident. ${ }^{13}$ Aggression in sport is not only understood through these definitions but an analysis of the theories behind the concepts can help to describe the motivation and causes for such behavior.

Theories of aggression in sport

There are multiple theories about aggression in sports that have been described in the literature to explain aggression in sport and why the acceptance of these actions is increasing. ${ }^{11,15}$ Although these theories have been devised by various individuals there is significant amounts of overlap between the processes. ${ }^{32}$ The first theory mentioned is the frustration-aggression hypothesis developed by Berkowitz. ${ }^{15,30}$ This theory ${ }^{30}$ states that if a person is actively prevented from attaining his or her goals emotions of anger and frustration will begin to arise; and, as these feelings increase the chance that the person will react in an aggressive nature will increase. ${ }^{30}$ Leith $^{35}$ examined Berkowitz's ${ }^{30}$ theory using high school age males $(N=10)$ to determine if specific independent variables would influence athletes displayed aggression. The first variable was activity strategy which had three conditions: (1) cooperative where the athlete was working alongside a confederate, (2) competitive where the subject was working against the confederate, and (3) competitive-aggressive where the confederate would employ aggressive actions in an attempt to win. ${ }^{35}$ The second variable, the outcomes of these tasks, was decided prior to the beginning of the experiment so that some subjects would be successful and others would not. Finally, the athlete's level of arousal was determined prior to and following 
the result. Using a self-report measure athletes rated their current level of aggression. Results revealed that those participants in the competitive or competitive-aggressive tasks were far more likely to report higher levels of aggression following the conclusion of the activity. ${ }^{35}$ The results also showed that the subjects were less likely be aggressive if they had been successful on the task. ${ }^{35}$ Berkowitz's ${ }^{30}$ theory when examined in hockey, has shown that athletes will behave far more aggressive in certain situations, for example when there was a large score differential, if they were playing in away games, losing, and finally the third period of play. ${ }^{15}$ These three studies have some important and similar findings since researchers found that regardless of the age of the participants, either high school age males or professional hockey players, the context of the activity greatly influenced the response, specifically aggression.

The second theory that has been used to describe aggressive tendencies in sport is the social learning theory. ${ }^{15}$ According to the Bandura's ${ }^{15}$ theory people learn and adopt aggressive behavior by observing others and then decide whether or not to adopt the behavior based on the outcome of the original situation. An example of social learning occurs in sport when an individual's observation of aggressive actions results in positive outcomes or the desired goal for the perpetrator. If the aggressive behavior is seen by others as a method to obtain similar outcomes then social learning has occurred. Unlike the research that has been performed on the frustration-aggression theory there has been little performed on the social learning theory in the sporting context. Most of the findings indicated that attitudes, personality, and personal behaviors are highly influenced by a number of close personal relationships, culture and society. ${ }^{15}$ Essentially if an athlete believes a specific aggressive act will obtain a desired outcome, such as a goal or a 
winning result, the individual is much more likely to proceed with this action if he or she has seen positive results by others in similar situations. However, if the athlete is unsure of the consequences the likelihood of aggression is significantly less. ${ }^{32}$

A third theory that has been used to describe aggression is the script theory. ${ }^{36}$ The script theory was developed by Huesmann ${ }^{36}$ and states that when people, specifically children, see violence in society or during their daily lives they cognitively create aggressive scripts that serve to regulate behavior. The individual first creates a script for a specific situation and then assumes a part in the script. During social development these scripts are stored and to be utilized at a later time when a similar situation arises to guide the social behavior. ${ }^{36}$ The more frequently these scripts are recalled the stronger their associations to specific situations become and the more readily they can be recalled. When a child witnesses a situation in which aggression has been advantageous a script will be created that places the child in the role of the aggressor. ${ }^{36}$ This script can then be recalled at a later time when dealing with a similar situation and the child will assume that aggressive status. ${ }^{32}$ In athletics this theory would function similar to the social learning theory.

Gee and Leith ${ }^{15}$ have examined professional hockey in an attempt to determine which of the previously described theories best describes aggression in athletics. This research is important since it would provide strong evidence supporting a possible explanation to a cause of aggression in sport participation. The authors have theorized that birthplace may play a role in the level of aggression displayed in professional hockey. ${ }^{15}$ To test this theory Gee and Leith ${ }^{15}$ have used penalty records from a single season of professional hockey. There were 2185 penalties recorded on the season. Their 
research focused on whether there was a difference in the displayed aggression between North American and European born players in the National Hockey League (NHL). ${ }^{15}$ These findings indicated that the North American born players displayed more aggression than the rookie European players but not the veteran European players supporting the social learning theory. ${ }^{15}$ The veteran European-born players have been in the league longer and therefore have been exposed to the behaviors much longer for a more time than their rookie counterparts and thus social learning has occurred. ${ }^{15}$ The authors believe that the NHL's pro-aggressive attitudes and acceptance positively reinforces the aggressive tendencies and therefore creates the likelihood that the behaviors will perpetuate via the social learning theory. However, their research also supported the possibility that certain situations were more likely to result in an aggressive response partially supporting the Frustration-Aggression hypothesis. ${ }^{15}$

A second investigation into the theories of aggression reported similar findings to those presented in the research performed by Gee and Leith. ${ }^{15}$ In their review of the literature, Gee and Leith, described a study ${ }^{37}$ performed on aggressive tendencies learned from violent video games. This research clearly demonstrated the social learning theory as applied to general daily living. The authors, Anderson and Dill ${ }^{37}$, utilized 227 undergraduate students ( $N=78$ males, $N=149$ females) with an average age of 18.5 years. The subjects completed a number of measures that were designed to quantify the amount of time spent playing violent videogames, level of trait aggression, delinquency and irritability. ${ }^{37}$ The findings in this study indicated that violent video gaming and aggressive personality separately and jointly explained a majority of the aggressive behavior and delinquency. ${ }^{37}$ The authors did find that an association between glorified 
violence in games and aggression does exist; which supports the theory that viewing accepted violence can contribute to an aggressive personality supporting the idea of the social learning theory. ${ }^{37}$ In athletics aggression is often praised by spectators and coaches for the favorable results creating a situation that fosters the idea that violence and confrontational actions are necessary to obtain acceptable outcomes. Those individuals who witnessed these instances of aggression were likely to adopt these strategies and utilize them in future situations. Pro-aggressive attitudes in sport were more likely to perpetuate the occurrence of aggressive by creating a social learning perspective. ${ }^{15}$ In addition to the numerous theories that have been created to describe aggressive behavior there were various other major influential factors that may predispose an act of transgression.

Factors that influence aggression

Contextually, aggression can be influenced by numerous intrinsic and extrinsic factors. As stated previously, the situation that the athlete finds themselves in, such as losing a game or failing at a task, can trigger responses of aggression. ${ }^{15}$ In addition to these extrinsic factors there are numerous intrinsic factors that can influence an athlete to respond aggressively. One of the most extensively researched factors in relation to aggression is an individual's gender. ${ }^{38} \mathrm{~A}$ number of innate psychological physiological and anatomical factors that play into display of aggression and responses include personality traits, attitudes that are held about the current situation, and personal and ethical values have been examined. ${ }^{32}$ For example, in Anderson and Bushman's ${ }^{32}$ review of human aggression they reviewed research concerned with gang-related violence and 
aggression. In additional to cognitive factors shaping aggressive behavior it's been shown that gender plays a major role in the display of aggression.

Personality type and gender are two of the predisposing factors that have been thought to influence the displays of aggressive behavior; therefore, Burton, Hafetz and Henninger ${ }^{38}$ examined the differences in the display of aggression in males and females in relation to a number of personality factors. The researchers utilized 134 college age students ( $N=93$ female and $N=41$ males) with an average age 20 years. The participants were required to complete out six self-report questionnaires including the Relational Aggression Questionnaire, the Physical Aggression Questionnaire, NEO Five-Factor Inventory for personality type, the Beck Depression Inventory and the Anxiety Inventory. ${ }^{38}$ The data was then examined in relation to gender across the various personality factors, which were: agreeableness, extraversion, conscientiousness, openness, depression, anxiety, and interpersonal skills. The relevant findings of this research indicated that personality types and gender played a major role in the expression of aggression in the sample population. Both genders displayed physical and verbal aggression. ${ }^{38}$ However, it has been reported that men displayed higher levels of physical aggression which is consistent with previously performed research. ${ }^{16}$

One personal factor that has been linked to aggression is high levels of trait aggression. ${ }^{32}$ Having high levels of trait aggression describes the personality of a person with a high proneness towards aggression. Researchers Buss and Perry ${ }^{16}$ have defined trait aggressiveness as the inclination to engage in physical or verbally aggressive actions, hold hostile cognitions, and experience and express anger. High levels of trait aggression are more likely to cause individuals to react in specific ways that include 
being susceptible to hostile attribution and altered situational perceptions. ${ }^{18}$ Due to the findings in the literature most of the research conducted in this area has focused solely on the male gender.

Males, both men and boys, have repeatedly been shown to display far higher levels of physical aggression than female participants in social situations. ${ }^{38}$ Therefore, a great deal of research has been dedicated to investigating the relationship between males and aggression. Gidycz and colleagues ${ }^{39}$ performed a study that examined aggression in college-aged males. They examined a number of factors that have been theorized in literature to contribute to the perpetration of violence. The researchers examined whether alcohol use, fraternity membership, sexual experiences and reported aggression could accurately predict whether an individual would be a perpetration of violence. ${ }^{39}$ According to the authors males who are member of sport teams and fraternities are more likely to engage in aggressive and sexually coercive acts when compared to their unaffiliated counterparts. ${ }^{39}$ Gidycz and colleagues ${ }^{39}$ study's included undergraduate students $(N=425)$, some of which were involved in fraternities or sport teams, and utilized a prospective study design. Participants were interviewed on two occasions at the beginning of the study and then again three months later. The results indicated that if the participant reported events of aggressive actions prior to the beginning of the study the individual was more likely to have subsequent issues with violent behavior. ${ }^{39}$ This statement was validated by the high correlation between males reporting a history of verbal and physical aggression and the admitted use of violence and verbal aggression at the three month follow up. ${ }^{39}$ Therefore, athletes that have displayed highly aggressive 
behavior in the past are going to be more likely to continue these actions throughout their careers.

Physiological factors have been studied in those participants with highly aggressive personalities. ${ }^{40}$ Individuals with high levels of aggression have been found to be more likely have extremely elevated blood pressure as a response to emotional stimuli. This physiological response may predispose certain individuals for cardiovascular results. ${ }^{40}$ Research examining the relationship between physiological factors and aggression has been done by Betensky and Contrada. ${ }^{40}$ Their study ${ }^{40}$ utilized healthy female undergraduate participants $(N=63)$ at a major university with an average age of 19.38 years with no reported medical history of cardiac, psychiatric, or neurological conditions. The subjects then completed the Beck Depression Inventory, the Buss-Perry Aggression Questionnaire, a health and behavior questionnaire, and had their blood pressure measured and recorded ${ }^{40}$ Subjects were then asked to stand and speak about an event in the past six months that had made them feel depressed in order to elicit an emotional response. The results showed that those participants with higher levels of trait aggression, specifically those women who were more verbally aggressive, were at an increased risk for an exaggerated stress response to an emotional situation. ${ }^{40}$ These findings highlighted the physiological responses and highly aggressive personalities. ${ }^{40}$

Strength and body size has been examined as one of the possible indicators of physical aggression. The authors, Archer and Thanzami ${ }^{41}$, examined whether participants ( $N=88 ; M=26.01$ years old) physically stronger and heavier than their less developed counterparts would be more likely to report higher trait aggression. The results showed an association between strength, body size, strength, and aggression. ${ }^{41}$ The more aggressive 
participants were also heavier and stronger than their counterparts, which indicated that the more physically intimidating people were also more likely to report higher levels of aggressive actions. ${ }^{41}$ These findings showed stronger athletes may be more likely to display aggressive tendencies during sport participation when compared to their weaker counterparts. ${ }^{41}$ Due to their increased size these athletes can potentially seriously injure a smaller less aggressive athlete. ${ }^{41}$ Aggressive behavior in athletes has been an ongoing topic of research and findings reported in the previous study can highlight why it is so important both in social settings and on the field to prevent possible injury.

Measuring levels of trait aggression

According to Maxwell and Moores ${ }^{28}$ measuring aggression in sport is difficult. There are numerous methods of administration of the aforementioned task which can include interview, questionnaire assessment, and finally direct observation of the participant during either in a laboratory environment, such as during a constructed scenario, or in during actually life. ${ }^{42 .}$ The first two methods presented, interview and observation, can be both time consuming and due to the various definitions of aggression in sport may be difficult. ${ }^{28}$ Therefore, the questionnaires to measure aggression in sport are typically used more often than the observation and subsequent interview method. ${ }^{42}$ According to Suris and colleagues ${ }^{42}$ when attempting to determine which measure to utilize during research to consider a number of factors including the population that is being examined, the operational definition of aggressiveness, as well as the behaviors that may be manifested during the experiment. Five major measures have been used in the relevant literature to measure aggression in sports; these measures are: the Buss-Durkee Hostility Inventory ${ }^{43}$, the Buss-Perry Aggression Questionnaire ${ }^{17}$, Bredemeier Athletic 
Aggression Inventory ${ }^{44}$, which specifically measure aggression, and the Continuum of Injurious Acts ${ }^{45}$, and finally the Sports Behaviour Inventory ${ }^{46}$ that measure the perception of the legitimacy of one's actions during sport participation. ${ }^{28}$ The final two measures presented by the authors, the Continuum of Injurious Acts ${ }^{45}$ and the Sports Behaviour Inventory ${ }^{46}$ were not reviewed by Maxwell and Moores ${ }^{28}$ since they did not specifically examine aggression in sport.

Maxwell and Moores ${ }^{28}$ have presented an argument against the three major measures the Buss-Durkee Hostility Inventory ${ }^{34}$, the Buss-Perry Aggression Questionnaire ${ }^{16}$, Bredemeier Athletic Aggression Inventory ${ }^{44}$ and provided reasoning for creating a new tool to examine aggressiveness in athletics. One major issue with the Buss-Durkee Hostility Inventory ${ }^{43}$ or the Buss-Perry Aggression Questionnaire ${ }^{16}$ created in 1956 and 1992, respectively, is the age of the measures. A second issue is that the measures are not sport specific. Some of the items presented on these scales do not apply to sports and therefore would make these measures difficult to use when examining sport specific actions and behavior. ${ }^{28}$ By not having items that relate to sports the measures could be difficult to adequately assess aggressiveness of athletes during sport participation. The Bredemeier Athletic Aggression Inventory ${ }^{44}$ has been extensively used in the research to examine aggression in sport however it has been reported that the numerous issues exist including questionable internal reliabilities for some of the scales. Also, the authors report that the numerous prompts may seem to be related to other traits such as anxiety or the control of one's emotions. ${ }^{28}$ Finally, Maxwell and Moores ${ }^{28}$ state that some of the items on Bredemeier's scale ${ }^{44,45}$ do not account for the inherent differences in the rules of sports. 
Therefore, due to the shortcomings of the aforementioned scales Maxwell and Moores ${ }^{28}$ created a twelve-item measure, the Competitive Anger and Aggression Scale (CAAS), that assesses both the traits of anger and aggressiveness in sport. There are six items dedicated to aggression and to anger. ${ }^{28}$ However, when examined in the scope of this current research the six items dedicated to anger will not be included in the study. The authors ${ }^{28}$ created fifteen items that could potentially be included on the scale with wording that allowed the prompt to be applied to any number of scenarios in a variety of sports and recipients of the aggressive action. If the item created was not applicable in all sports or if it focused on one individual it was dropped from contention to be included. It was this process that resulted in the final twelve item scale. ${ }^{28}$ The test-retest validity was determined to be acceptable using a sample of athletes $(N=133)$ for the whole measure (.88), the aggression subscale (.84), and finally the anger subscale (.86), which were considered to be acceptable results. ${ }^{28}$ The authors of the CAAS ${ }^{28}$ utilized the Buss and Perry Aggression Questionnaire ${ }^{17}$ to determine the concurrent validity of the new measure with moderate correlations between the two scales. In order to perform the discriminant validity the authors utilized a multivariate analysis of variance. ${ }^{28}$ The subscale scores on the Competitive Aggressiveness and Anger Scale were used as the independent variable and then the athletes $(N=44)$ classified by their peers as calm $(n=17)$, neutral $(n=15)$, and fighters $(n=12)$ during sport participation. The MANOVA indicated that a significant effect for group assignment existed and following post hoc analyses the fighter group scored significantly higher than those in the calm or neutral group. ${ }^{28}$ This finding is important in that it shows that the measure is able to discriminate between those athletes that are considered to be aggressive during sport participation and 
those that are not. The findings of this study indicated that this measure is an acceptable measure of anger and aggression in sport. The authors ${ }^{28}$ state that further research is necessary in order to support these findings.

Based on the results presented by the authors ${ }^{28}$ of the CAAS this measure appears to be an acceptable measure of the traits of anger and aggressiveness in a sport specific tool. The authors ${ }^{28}$ have used athletes from various team sports during the creation of their new measure which should all the assessment tool to be used in all of the sports that are to be included in the current research. By including a sample of students that were previously involved in various team and individual sports the authors have shown that the measure has the ability to applicable to a variety of sports. ${ }^{28}$ Also, the measure was created to measure aggressiveness, which is considered to be an attitude, rather than aggression in sport. The CAAS ${ }^{28}$ was shown to have a high correlation with the scales of the Buss and Perry Aggression Questionnaire ${ }^{16}$ showing that the measure is an acceptable measure of aggressiveness. ${ }^{28}$ Finally, the measure is significantly newer than any of the aforementioned measures of aggression, which means that the prompts on the $\mathrm{CAAS}^{28}$ contain wording that is current and easy for the participants to comprehend which has been suggested to potentially be problematic. Another aspect of this scale that is an improvement over other scales of aggression and aggressiveness is that the scale is only twelve items requiring less of the participant's time making participation in this research significantly easier. Therefore, this measure should be an acceptable tool to utilize in the measurement of aggressiveness in the current study. Aggression in sport 
When examining aggression in sport researchers have been attempting to further their understanding of the internal and external processes resulting in this unethical behavior. In the literature the term "aggressive athlete" has been used to describe individuals that are reacting to provocation or acting as the instigator by using physical or verbal force. ${ }^{4}$ Donahue, Rip and Vallerand ${ }^{33}$ examined whether an individual's identity could influence the level of aggression displayed if this concept was under attack. Findings indicated that when the idea of the athletic identity was under a "perceived attack" the athlete was more likely to retaliate with an unethical response. ${ }^{33}$ Maxwell and Visek ${ }^{13}$ also looked at this concept by examining examined the relationship between aggressiveness, anger, identity and professionalization in rugby. Aggressiveness in this experiment was defined as the characteristic to become aggressive or an acceptance of the use of aggression. ${ }^{13}$ The authors' findings indicate a relationship between aggressiveness, professionalization, being taught how to execute unsanctioned behaviors, and aggression. ${ }^{13}$ It should be noted that the authors have reported that anger is often is present prior to an aggressive action but not necessarily a requirement. These results are not surprising since it has been theorized that high trait anger and aggressiveness are two of the most important factors that predict aggressive actions. ${ }^{13}$ These two predecessors of aggression have been shown in both athletes and non-athletes in prior research. In addition to the personality of athletes possibly influencing the level of aggression during sports there have been various other factors implicated in the research.

Examining coaching behavior can offer insight into the athlete's mentality and the reasoning for aggressive and assertive actions. Coaches often act as the leader for the 
team's mentality and if he/she is emphasizing use of aggressive actions during competition the athlete is more likely to act in such a manner. ${ }^{47}$ Justification provided by athletes to explain aggressive actions may be as varied as the action itself. However, it stands to reason that one of most prominent factors influencing the athlete's behavioral decisions is the coaching staff. ${ }^{47}$ If a coach shows indifference towards aggressive actions on the part of the athlete this may result in the belief of the athlete that he or she is positively reinforcing the act of aggression directly relating back to the social learning theory. On the other hand if the coaches minimize the consequences by either ignoring or reinforcing these actions were correlated with higher incidents of aggression in both boys and girls sports. ${ }^{48}$ A similar research study examined high school and club soccer teams and the predictors of aggression. The first relevant findings is that the game strategy, determined by the coaches, and was related to the likelihood that an athlete will aggress during play. ${ }^{47}$ If the coach advocated for aggressive actions during play the athlete were more likely to engage in such behavior. The coach's norms and accepted behavior strongly influences the athlete's moral decisions. ${ }^{47}$

The aforementioned literature has presented evidence that aggression is becoming a major issue in all levels of sport participation. The incidents of aggression are not limited to any specific sport in particular but in fact affect nearly all sports. ${ }^{7,13-15}$ This finding indicates that there is a need for some type of intervention strategy for the athletes. It must be mentioned that one possible outcome of an aggressive act may be injury. If an athlete is behaving in an aggressive fashion he or she may be creating a situation that could result in a personal injury one that affects another individual. 
Therefore, it stands to reason that further investigations are warranted within this area to provide information on how to prevent aggression during sport participation.

Aggression and injury in sports

In the research there has been extensive investigation into the psychosocial precursors to injury. ${ }^{4-8,19}$ It is the findings of these inquires that helped authors Williams and Anderson ${ }^{8}$ create their proposed theoretical model of the relationship between psychosocial variables, stress response, and injury. According to their Stress-Injury model ${ }^{8}$ there are three major factors that play a role in the athlete's response to an athletic situation: coping resources, a history of stressors, and personality factors. The model suggests that these three factors can influence how an athlete will respond in a given stressful situation. ${ }^{8}$ The theory states that those athletes who have a history of numerous stressors, a personality type that would intensify a stress response, and limited available coping resources will exhibit a more pronounced physiological response to a stressful situation. It is this enhanced physiological response and subsequent cognitive disruption that is a possible predisposition to injury. ${ }^{8}$ The authors ${ }^{8}$ further reported that during sport participation the stress response is more likely to be manifested as a physiological and attentional response. The theory linking personality to injury rates states that while desirable or positive traits are likely to decrease potential for incidents those athletes with high levels of negative factors, such as anxiety or aggression, are more likely to sustain injuries during participation. ${ }^{8}$ The findings in the literature indicate that there is a strong possibility that personality type may play a major role in the incidence of injury. 
Fields and colleagues ${ }^{6}$ examined a sample of recreational runners in a running club $(N=40)$ with an average age of 37 . The goal of the study was to determine if there was a relationship between the number of injuries reported and athlete's personality type. Specifically, the authors wanted to determine if those athletes that were found to have a type A personality were more prone to injuries (those individuals with type A personalities typically have a high level of trait aggression). ${ }^{6}$ The authors distributed the Type A Self-Rating Inventory (TASRI) to identify those runners with a type A personality. Participants were classified as having a type A personality if their score was greater than 120 on the TASRI. ${ }^{6}$ Once completed the participants were asked to keep a training journal for a calendar year to document when they sustained an injury. ${ }^{6}$ The authors ${ }^{6}$ defined an "injury" as a musculoskeletal problem that occurred during participation that resulted in the athlete having to refrain from participation for one or more days. Of the 40 participants fourteen scored 120 or greater on the TASRI and therefore were identified to have a Type A personality. The results of the study showed that as the score on the TARSI increased the number of reported injuries did as well. ${ }^{6}$ Since this study did not examine trait aggression specifically a true conclusion cannot be determined; however, the results do offer compelling evidence to support the theorized link of aggression and injury due to the correlation between Type A personalities and the incidence of injury.

In psychological literature the relationship between aggression and injury has not been extensively examined. ${ }^{4,19}$ Thompson and Morris ${ }^{5}$ examined the importance of psychological variables as predictors of injury in adolescent football players. Using a group of high school football athletes $(N=240)$ the study wanted to determine if there was 
a relationship between aggression, attention, or stressful life events on the incidence of injury rates. ${ }^{5}$ Using self-report measures and a number of physical assessments the authors collected their prescreening data. ${ }^{5}$ The number of injuries incurred by each individual athlete was collected from the coaches and athletic trainers on a weekly basis. The authors' findings showed that between 21 and $99 \%$ of the risk of injury could be related to the interaction between position played, age, and psychological variables. A negative association was found with attention and injury rates indicating that as the athlete's attention was increased the likelihood for sustaining an injury decreased which was also found to be independent of life events. ${ }^{5}$ The relationship between aggression and injury in this study was interesting in that if an athlete displayed either too much or too little aggression the possibility of sustaining an injury increased. ${ }^{5}$ By acting too timidly or far too aggressive the athletes place themselves at a higher risk for injury during sport participation. ${ }^{5}$ Clearly, based on the findings of the aforementioned studies that psychological factors play a major role in the occurrence of sports related injury and that these factors can affect all athletes regardless of the sport they participate in.

Emery and colleagues ${ }^{7}$ examined the relationship between the acceptance of body checking, empathy, and aggression. The authors examined two types of youth hockey leagues in Canada, checking $(N=138)$ and non-checking leagues $(N=145){ }^{7}$ The study followed the athletes throughout one of the hockey seasons to obtain injury reports sustained during practices and game. Emery and colleagues ${ }^{7}$ also administered four selfreport questionnaires to the athletes that included a medical questionnaire, The Body Checking Questionnaire, Empathy Index for the Children and Adolescents, and The Buss-Perry Aggression Questionnaire. ${ }^{16}$ The results indicated that the aggression score on 
the Buss and Perry Aggression questionnaire ${ }^{16}$ were significantly higher than in the league that allowed body checking when compared to the participants in the nonchecking league. The authors found no difference in the levels of empathy between the two groupings. With relation to injury level the authors found no significant relationship between the level of aggression and injury rates. ${ }^{7}$ The authors have stated that as the aggression level increases there is a greater chance for injury causing behaviors. The results reported by Emery and colleagues ${ }^{7}$ indicated that it's the less aggressive players that are more likely going to be the recipients of the injuries rather than those aggressing. The authors have acknowledged that there were significant limitations in their study including sample size and possible selection bias, which may have altered their results. ${ }^{7}$ The authors also stated that more research needs to be conducted in this area to fully understand whether a relationship exists between trait aggression and injury. Schewebel and colleagues ${ }^{49}$ examined some risk factors specifically in youth soccer, specifically pre-adolescents. The participants in the study were eleven or twelve year-olds $(N=60)$ over the course of a soccer season. They examined various variables as potential predisposing factors injury including aggression. Their findings indicated those with greater skill and less experience playing sport were the greatest predictors for injury. ${ }^{49}$ Similar to the findings of Emery and colleagues ${ }^{7}$ this group found that aggression did not appear to be a risk factor for injury and neither did inhibition or risk-taking actions. ${ }^{49}$ The psychological precursors of sports-related injury can be one of the most difficult factors to preventatively control for and thus, deserve further investigation. ${ }^{49}$ As seen in the literature there are conflicting findings when examining the relationship between injury and aggression in sports. This topic needs to be further investigated in order to establish 
this relationship. If injury rates are in fact related to the level of aggressiveness then it may be possible to implement an intervention strategy to change the level of aggressive behaviors in sports and therefore affect the number of injuries sustained by participating athletes.

\section{INJURIES IN ATHLETICS}

Injuries in athletics are common, which has prompted investigations to study the causes, and factors that predispose athletes. The NCAA injury surveillance program began in 1988-1989 and collected injury data for sixteen years. The program recorded approximately 182,000 injuries across one million exposures. ${ }^{2}$ The creators of the program defined an exposure as a single athlete participating in one day or game of their sport. ${ }^{2}$ Hootman, Dick, and Agel ${ }^{2}$ have presented the data from the surveillance program for fifteen sports including football, basketball, lacrosse, soccer, men's wrestling, men's ice hockey, baseball and women's gymnastics, women's volleyball and softball. When examining the relationship between aggression and injury it is important to have examined the additional factors that can influence occurrence rates.

The findings reported by Hootman, Dick, and Agel $^{2}$ from the NCAA indicate that injury rates were far higher during exposures in a game than in practice, 13.8 and 4.0 injuries per 1000 exposures respectively. Also, the findings showed that athletes were more likely to receive an injury during preseason practices than during in-season or postseason. Per 1000 exposures, there were 6.6 injuries during preseason, 2.3 during inseason, and finally 1.4 during the postseason. ${ }^{2}$ Football was found to have the highest injury rates in both games and practice. Football practice reported 9.6 injuries per 1000 exposures and 35.6 injures in game time settings while baseball had the least amount of 
injuries. ${ }^{2}$ Over the extent of the sixteen years of the program the results have remained relatively stable. However, the assessment has shown that the majority of the injuries are related to the lower extremity with ankle sprains being the most common injury accounting for fifteen percent of all injuries. ${ }^{2}$ The underlying cause of these injuries was not examined by the authors, as this was a purely epidemiological study. ${ }^{2}$ A number of further analyses were conducted on all the sports included in the original study. The findings all indicated that sports are relatively safe yet further preventative action needs to be taken to prevent the relatively small incidents of injury that occur.

As previously stated injuries are relatively commonplace during athletic participation; therefore the safety of the athletes during athletic participation should be a top priority. By examining the underlying causes of injury and addressing the factors that predispose an athlete to getting hurt and initiating preventative measures the athletes are more likely to remain safe during the course of practice or competition. If the research is indicating that the rate of injuries is the result of a psychological factor it is important that specially trained members of the sports medicine team be alerted to these findings and therefore may implement some mechanism to prevent these processes. Factors such as morality and moral disengagement have been examined in sport as a precursor to aggressive behavior predisposing some to athletic injury. Therefore, it is necessary to investigate this relationship as a method of prevention.

\section{MORAL DEVELOPMENT}

Moral development across the lifespan is an important process that occurs as a person ages and matures. ${ }^{50}$ Moral development is described as the changes that occur in the thoughts and actions based on values and cultural norms. It is one's culture and 
surrounds that serve to define the norms and what behaviors are deemed to be acceptable ${ }^{51}$ It should be noted that simply examining the society that an individual has been raised may not be the strongest predictor of how a person will respond to a specific situation. ${ }^{52 .}$ When attempting to judge one's response to a dilemma presented in a social situation the moral reasoning and development of the individual should be examined. ${ }^{51}$ Therefore this course should be examined as morality plays a major role in every situation in; therefore, various theories have been presented in the literature..$^{51,53,54}$ Theories of moral development should focus on two aspects the content and the structures of the judgments that are being made. ${ }^{55}$ Kohlberg ${ }^{51}$ presented his theorized progression of moral development across the lifespan, which is composed of three levels each with two stages during each level. According to this theory there are three definitive factors that define the progression of his moral development process. The first characteristic of Kohlberg's theory ${ }^{51}$ is that each stage represents an organized system of thought indicating that the individuals in a specific stage are consistent in their moral judgment processes. The second point is that people will always progress forward through the stages. Finally, a person will always attempt to function at his or her highest stage, which requires mastery of the thinking processes of the lower stages ${ }^{51}$ As previously stated there are three moral levels that compose Kohlberg's theory ${ }^{51}$ with two individual stages within each for a total of six stages.

The first level within Kohlberg's theory ${ }^{51}$ is the Pre-conventional stage and is defined by a child responding to cultural rules and labels of what is deemed to be good and bad. However, the child only understands either the positive or negative physical outcomes of the action. The two stages within this level consist of the punishment-and- 
obedience orientation and the instrumental-relativist-orientation. The first stage, the punishment-and-obedience orientation, is described by one's acknowledgement of the appropriateness of the action based on the physical consequences. Thus, physical punishment will result in action avoidance. ${ }^{51}$ The second stage of the first level is the instrumental-relativist orientation which exists when one realizes that the proper action will ensure one's needs are met and occasionally assist the needs of others. ${ }^{51}$ The second level is known as the Conventional level which is marked by ensuring that the expectations of others in one's family, community, or culture are perceived as acceptable. It is also noted in this stage that one may feel he or she is loyal to appropriate social order. ${ }^{51}$ The third stage is the interpersonal concordance orientation which is defined as moral behavior pleases other members of the society and therefore is positively reinforced through feedback from others such as "good" or "nice." The fourth stage is termed law and order orientation. This stage is geared towards the maintenance of the social order by respecting the governing authority. ${ }^{51}$ The final level is termed either the Post-conventional, Autonomous, or Principled Level and is marked by efforts to define the application of moral principles apart from the authority of the governing groups. The fifth stage, or the first stage within the fifth level, is known as the social-contract orientation; during this stage a person attempts to define the morally correct action in terms of the individual rights that have been allotted by the governing bodies of the society. ${ }^{51}$ According to Kohlberg ${ }^{51}$ this mentality defines the American government and the Constitution of the United States of America. The final stage of Kohlberg's theory ${ }^{51}$ is the universal-ethical-principle orientation which has been defined as when the correct decision is made by one's conscience as defined by society's norms and regulations. ${ }^{51}$ 
These thoughts and decisions are marked by abstract thought and reasoning to appeal to what one considers being socially and morally acceptable and irreprehensible. ${ }^{51}$

Haan ${ }^{54}$ has presented a similar theory on the development and maturity of the moral self. According to this theory the goal of the moral development is to utilize fair and impartial moral solutions in one's life and dialogues. ${ }^{54}$ This theory also is composed of three phases, similar to Kohlberg's ${ }^{51}$, however there are only five levels. The first phase of Haan's theory ${ }^{54,56}$ is the assimilation phase in which the individual aims to create a moral balance for the main benefit of the self. In this theory Haan ${ }^{54}$ has defined moral balances as an acceptable moral outcome. There are two levels within this phase; level one has been termed power balancing and level two is the egocentric balancing. The first level, the Power balancing, is defined when the moral decisions are made when the outcome benefits the individual. ${ }^{54}$ The second level, egocentric balancing, which occurs when the individual can acknowledge the personal interests of others; however, any moral decision that will be made during this phase will only occur if the outcome also benefits the individual as well. ${ }^{54}$ The second phase is the Accommodation phase which is marked by the individual striving to make moral decisions that benefit a wider group or population. ${ }^{54,56}$ The third level of Haan's theory ${ }^{54,56}$ is named harmony balancing and states that the individual will acknowledge but not able to differentiate a group's interest from his or her own personal interests. The fourth level is known as the common interest phase and is defined by the individual now being able to determine the difference between one's self interest and group interests and therefore he or she will aim to find the most morally acceptable outcome. ${ }^{54,56}$ The third, and final, phase of moral maturity according to Haan ${ }^{54}$ is Equilibrium phase which is marked by the self attempting to 
optimize the moral interactions for the desired outcomes impartially. The fifth level is known as the mutual interest balancing and finds an individual recognizing him or herself as a force that can improve or deter the moral balances and must act accordingly ${ }^{54,56}$ It should be noted that both theories ${ }^{51,54}$ were developed with findings based on everyday life situations. For example, Haan ${ }^{54}$ has examined her theory within a heterogeneous sample of adolescents and focused on the interpersonal relationships through an interview process. The situations that occur during sport are significantly different from those that would be encountered during typical situations in society. Therefore, further examination has been conducted on the topic of moral development in sport to determine whether involvement promotes or serves to deter moral development.

The effect of sport on an individual's moral development has been thoroughly examined in the literature with inconclusive findings. ${ }^{50,53,55-57}$ According to Camire and Trudel ${ }^{58}$ it is often assumed that the sport participation results in positive moral development; however further examination of the studies this assumption is not always supported. Due to the inconclusive findings it is clear why this topic has been of great interest to researchers. ${ }^{57}$ According to Bredemeier and Shields ${ }^{57}$ examining moral development in sport provides a unique context since there are situation that regularly occur in sport that would never be encountered during everyday life. Thus, it is believed that sport evokes moral patterns that are different from general life situations. Therefore, to investigate this theory Brdemeir and Shields ${ }^{57}$ examined a sample of high school athletes $(N=100)$ to determine whether those individuals participating in sport differed from their nonparticipating counterparts in their moral maturity. The sample population used consisted of both collegiate $(n=50)$ and high school $(n=50)$ of this population there 
were nonatheltes $(n=40)$ and athletes $(n=60) .{ }^{57}$ The study was performed by having each participant respond to four moral dilemmas; two were sport related while the remaining two did not. ${ }^{57}$ The findings of this study indicated that those athletes participating in contact sports, which was basketball, were shown to operate at significantly lower levels of moral reasoning than either the nonathletic group or the participants involved in a noncontact sport, swimming and diving. ${ }^{57}$

Bredemeier ${ }^{53}$ examined the relationship between moral reasoning and various action tendencies which are displayed as a result of a specific moral dilemma presented. The research examined how a sample of fourth through seventh graders $(N=106)$ responded to a number of prompts on the Children's Action Tendency Scale (CATS) and Scale of Children's Action Tendencies in Sport (SCATS) which both measured the behavioral responses displayed in ten conflict situations. The items that are included on the SCATS are set in sport context while those on the CATS are daily life situations. For the researcher to assess the level or moral development, the participants were interviewed and evaluated on their responses to four moral dilemmas. ${ }^{53}$ The responses on the items measure the level of physical or nonphysical aggression or submission. Finally the researcher examined the relationship between the stage of moral development and the responses on the CATS and SCATS measures. ${ }^{53}$ The findings indicated that moral reasoning abilities were predictive of the behaviors assessed on the SCATS and CATS. Assertion, which is considered to be morally beneficial since both parties may benefit, was shown to be positively related to moral development. ${ }^{53}$ Therefore, those participants that were able to make decisions that not solely for the benefit of themselves. However, it was shown that those subjects with lower moral reasoning abilities were more likely to 
display aggressive tendencies. This finding shows that those participants that would act outwardly aggressive towards another individual have more difficulty finding a moral balance with their actions. ${ }^{53}$

It has been suggest in the literature that athletes may not be able to differentiate between the appropriate moral responses in sport and in general life. ${ }^{\text {Jones \& McNamee }}$ Thus, this study indicate that participation in sport, specifically high contact sports such as basketball or football, may in fact prove to be detrimental to the moral development. Similarly, it has been shown by Skelton ${ }^{59}$ that the moral responses displayed by football players in high school may carry over from the sport setting into the moral behaviors that are displayed during a typical day. It has been recommended by Camire and Trudel ${ }^{58}$ that educators and coaches include some for of morality lessons when interacting with athletes to improve the gamesmanship and increase moral development in high school athletes to bridge this apparent disconnect between the settings of everyday life and sport.

\section{MORAL DISENGAGEMENT}

Morality, or moral behavior, has become a major area of interest in the psychological research is described by the social cognitive theory of the moral self states that moral reasoning is linked to moral action through various active self-regulatory mechanisms. ${ }^{24-27}$ According to Albert Bandura, ${ }^{24}$ development of morality occurs as the self creates guidelines that define acceptable and unacceptable conduct. When a person is making a decision the self-regulatory mechanism comes into effect by weighing the positive and negative consequences. Using this information a decision will be made. The theory further states that morally acceptable decisions should result in positive feelings and increased self-worth and satisfaction thus reinforcing the moral code. ${ }^{23-25}$ However, if 
a decision violates the accepted moral code the result will be self-condemnation and therefore will be avoided in the future. This process however is not necessarily automatic and the self-regulation can be dismissed and conscious influences can override the moral code. $^{24}$

Bandura's ${ }^{22,24}$ theory states that moral agency has two tasks: a proactive ability and an inhibitive ability. This proactive ability or prosocial behavior for moral agency is the ability for a person to act morally in a situation. ${ }^{24}$ These behaviors benefit the individual or the group the individual belongs to. ${ }^{24}$ The inhibitive or antisocial behavior of morality on the other hand refers to the actions that would hurt or injure the recipient or group. This antisocial behavior is related to the mechanisms of moral disengagement since it is the ability to act inhumanely and to transgress against others. ${ }^{24}$ People with high levels of antisocial behavior are more likely to act with aggressive actions. ${ }^{41}$ In their literature review Sage and Kavussanu ${ }^{60}$ reported that research has found that levels of prosocial behavior are not related to levels of antisocial behavior; therefore, it can be assumed that while people may display high levels of prosocial actions it is still possible to show antisocial behavior. ${ }^{60}$

There are various methods allowing a person to consciously deactivate the mechanisms of moral behavior collectively termed moral disengagement. ${ }^{24}$ Moral disengagement is defined as a self-regulatory procedure that occurs with cognitive restructuring of an action, decision, or behavior. ${ }^{24}$ This process results in altering the regulatory mechanisms formed according to the social cognitive theory and one can actively disengage themselves from their behavior. ${ }^{24}$ When one can actively cause some form of harm to another with a clear conscience there are likely moral disengagement 
mechanisms at work. ${ }^{61}$ Bandura ${ }^{23,24}$ has identified eight processes, which are enacted to morally disengage from decisions that would be considered immoral. It should be noted that moral disengagement is not a single decision but a collection of various mechanisms that affect the subject's complete perception of a situation. ${ }^{24,61}$ Moral disengagement serves to check the inhibitory function of the moral self-regulation by essentially acting as a moderator between the behavior and the subsequent emotional response that would normally serve to regulate it. ${ }^{24,27}$ In order to morally disengage oneself from an immoral action one of the eight mechanisms of moral disengagement must be used.

Mechanisms of moral disengagement

Bandura ${ }^{24,27}$ has theorized the mechanisms of moral disengagement in an attempt to explain why people can selectively disregard their moral self-regulation.

Understanding these processes will illustrate how the theory of moral disengagement applies when overriding the act of moral agency. ${ }^{62}$ These mechanisms allow individuals to participate or perform in self-serving actions rather than act as they deem morally acceptable ${ }^{24,60,62}$ The eight mechanisms serve as various methods that allow for cognitive restructuring of the action to suit the aggressor's moral code. ${ }^{27}$ The theory behind moral disengagement states that people will not engage in activity that he or she considers to be morally reprehensible unless the action has been justified. ${ }^{24}$

The eight processes of moral disengagement can be divided up into four distinct groupings. The first set is composed of three processes focusing on the act itself. ${ }^{27}$ Moral justification, euphemistic labeling and advantageous comparison all serve to alter one's perception of a negative behavior by changing the act to seem acceptable. ${ }^{27}$ Moral justification occurs when redefining transgressive behavior into one that is personally and 
socially accepted by claiming that the action is valued. ${ }^{37}$ If the action is believed to be serving moral or socially worthy purposes the moral view of the self is preserved. ${ }^{24}$ In sports moral justification may occur if purposely injuring or cheating an opponent to protect a teammate or one's self-image. Claiming that an aggressive action was done for protection rather than to hurt an opponent would describe moral justification. ${ }^{27}$

The second process, euphemistic labeling uses language to disguise unacceptable behavior as less punishable. ${ }^{27,37}$ Language is an important tool in shaping views of specific thoughts or actions. Thus, simply changing the words used to describe an activity can alter the morality of it. Sanitizing language is important when employing euphemistic labeling. ${ }^{24}$ Sanitizing language occurs when more benign words are used to replace ones that are considered to be blameworthy ${ }^{63}$ In sports using terms such as "enhancement" to talk about steroids or "sidestepping the rules" for cheating are examples of euphemistic labeling. ${ }^{27}$ Furthermore, the use of an agentless passive voice is another tool for euphemistic labeling; which occurs when the speaker removes him or herself from the activity and places the blame on the other forces. ${ }^{24}$

Finally, the third process utilized is advantageous comparison in which a behavior is compared to a transgression far worse than the one in question. ${ }^{27}$ By comparing an immoral event to another that is far worse; the original event will pale in comparison. Utilization of this contrast can make inexcusable actions seem acceptable and even trivial. ${ }^{24,37}$ In athletics this mechanism occurs when an athlete views a lesser foul as acceptable when it was in retaliation for one that was far worse. If, for example, in soccer a player received a yellow card as the result of his or her response to a previous incident that resulted in a red card and the athlete does not view the response as morally 
unacceptable the mechanism of advantageous comparison is in effect. The sum of these three processes of moral disengagement function to change the perception of activity and create a less reprehensible image. While these three processes focus mainly on the act itself another set of processes are related to who receives the blame for the behavior. ${ }^{27}$

The second set of processes focus on the responsibility of the actions by limiting one's accountability and includes the displacement and the diffusion of responsibility. ${ }^{27}$ The first process, displacement of responsibility, occurs when believing that one's actions are the direct result of pressure from another party, individual or from society in general. ${ }^{27,37}$ If a perceived legitimate authority will be taking responsibility for an action individuals are more likely going to act in ways typically considered to be unacceptable. This process of self-exception from the activity permits a disengagement from the responsibility of the actions. ${ }^{24}$ In the context of athletics this tool for moral disengagement may be seen when one attributes aggression in sport to his or her coaches or teammates. The athlete believes that he or she is morally justified in his or her aggression since the decision to commit the action is not their own but some higher authority. $^{27}$

Diffusion of responsibility occurs when a group has divided an immoral action amongst themselves and everyone has a small role. By dividing of the whole task into a number of unimportant smaller roles individuals can participate in an immoral action since their contribution is very small. ${ }^{27}$ Moral responsibility is diminished by spreading the responsibility over a group of people such as during group decision-making or collective action allowing a sense of anonymity to the perpetrators. ${ }^{24}$ If the actions are divided amongst a large group of people the small contributions of activities seem more 
acceptable. In athletics if the team participates in some large immoral action each participant feels less accountable. According to the original theory, Bandura ${ }^{24}$ postulated that this mechanism takes advantage of the idea that if the process is subdivided amongst many people, such as across a sports team, each person's individual input is justifiable. ${ }^{24}$ This mechanism is more difficult to conceptualize in athletics on the field since it would require that a large grouping of people partake in some immoral activity. ${ }^{27,37}$ This example of moral disengagement can be better conceptualized in activities the athletes would take part in off the field for example if the team was to participate in hazing activities with freshman athletes. Other reports have made similar claims of linking moral disengagement and hazing. ${ }^{64}$

The third grouping of the processes of moral disengagement consists of one process distortion of consequences occurring when the results of one's actions on another are minimized or completely ignored which greatly reduces any possibility of selfregulation. ${ }^{27}$ Aggression towards others is easier if the subsequent result of the act is not visible since the emotional responses would have triggered the self-regulatory mechanisms and caused negative self-feedback. ${ }^{24}$ In sporting events this process of moral disengagement can be seen when athletes or coaches avoid learning the full extent of an action's outcome. ${ }^{37}$ For example, if a hockey player purposely slashes an opponent and avoids learning the resulting injuries sustained by the action he or she has avoided having to consciously accept consequences as their own action and therefore can accept the action as legitimate.

The final two of mechanisms of moral disengagement directly involve the victim or victims of the action and include dehumanization and attribution of blame. 
Dehumanization of the victims involves a complete removal of all human aspects of the individual and replacing them with animalistic qualities. ${ }^{27}$ Bandura reported that people will alter their actions based on the personal opinion of the opponent; viewing another person as a person will trigger an emotional response and therefore result in an empathetic reaction and moral regulation. ${ }^{24}$ If dehumanization occurs and all human traits are removed and the opponent is viewed with animalistic qualities it becomes easier to transgress against since the morality censure will not activate. ${ }^{24}$ For example, if an athlete uses a racial slur or views their opponents as an animal one may be more prone to aggress against the person since they are viewed as less than human. ${ }^{27}$

Attribution of blame is defined when an individual feels that he or she is truly a victim in a given situation and the behavior is blameless and the responses were justified. ${ }^{23}$ This process of moral disengagement occurs when the aggressor views the victim as the cause for their situation. ${ }^{24}$ Attribution of blame occurs in sporting events if an athlete blames another for an act of aggression due to some prior incident. When, in athletics, some offense is deemed legitimate and acceptable by the athlete as response to some earlier aggression the offense has been attributed to the actions of another. ${ }^{27}$ As can be seen from the descriptions of the mechanisms Bandura developed this theory to describe methods that would allow a normally moral person to commit actions considered unacceptable by typical standards. ${ }^{65}$ Moral disengagement needs to be examined in specific contexts to truly show how this process functions to describe the processes of moral behavior. 


\section{Moral disengagement in sports}

According to the literature, sport has become considered to be one of the forerunning causes of aggressive, or antisocial, behaviors; but, were originally considered to help in the development of many prosocial behavior characteristics including the virtues of loyalty, fairness, and cooperation..$^{22,60,66}$ Long and colleagues ${ }^{22}$ performed a qualitative study of the moral reasoning of young athletes performing at an elite level about the compliance and violations of the rules of sport. ${ }^{22}$ This study involved interviews with elite male adolescent athletes $(N=10)$ involved in various contact sports: soccer, judo, and rugby. ${ }^{22}$ Specifically, the research team included sports that were considered to require low moral functioning. Results revealed that the athletes displayed a type of morality, termed bracket morality, which is defined as a psychological action to separate their actions in sport from everyday actions. ${ }^{22}$ The researchers also found that the morality of athletes was heavily dependant on a number of factors including the social environment, the demands and orders of the coach, and peer influences. ${ }^{22}$ The authors divided the responses from the athletes into positive and negative behaviors; included under the negative behaviors was cheating behaviors and aggression towards opponents. The results of these interviews also showed that there are multiple mechanisms of moral disengagement that allow the athletes to violate the rules in their respective sports. ${ }^{22}$ All 10 of the athletes reported they had committed some transgression as a result of the coach's pressure to do so to win. This finding indicated that the athletes had attributed the action to their coach's pressure, which is the definition of the mechanism of displacement responsibility. ${ }^{22}$ Therefore, by operating under the impression that the coach was actually the one that caused the aggression the athlete has freed himself from 
the consequences. Similar to this finding, the results indicated that a number of transgressions, including physical and verbal intimidation, were committed since they were accepted by the team as normal behavior. Moral justification occurred when the athletes reported using aggression to ensure a victory. The athletes justified breaking the rules of their sport if they figured that it would ensure victory. ${ }^{22}$

In another similar research project Corrion, Long, Smith and d'ArripeLongueville ${ }^{23}$ interviewed athletes specifically about the mechanisms of moral disengagement. This study had a more heterogeneous sample which included both males $(N=12)$ and female $(N=12)$ between the ages of 20 and 27 years old, unlike the previous study ${ }^{23}$ that only included male participants. ${ }^{23}$ Choosing a qualitative approach enabled, participants to describe situations in which they infringed upon the rules. The researchers then reported the mechanisms that were the most prevalent responses. Results indicated that athletes employ displacement of responsibility, attribution of blame, minimizing consequences, and diffusion of responsibility most often. Euphemistic labeling was reported by twenty-three of the twenty-four participants. The mechanisms least reported were advantageous comparison and dehumanization. ${ }^{23}$ These results clearly demonstrate that a number of moral disengagement mechanism are at work during sport allowing the athletes to actively disengage themselves from moral self regulation and commit intentional fouls. ${ }^{23}$

The findings of both studies indicated that the athletes would use moral disengagement during competition. As seen in both studies, athletes were able to disengage their actions from their normal moral behaviors and commit various forms of transgression including physical aggression. ${ }^{22,23}$ One athlete, quoted in Long and 
colleague's ${ }^{23}$ study stated that “...there are a lot of little rules violations going on, like holding an opponent by his jersey... little rules violations are very common; it's normal..."(p. 339) This quote shows not only the commonality of transgressions in sport but that it may be believed to be acceptable by the athletes participating.

Morally disengaged people are far less likely to consider the well being of others when deciding how to behave toward them and thus increase the possibility of responding aggressively or using violence. In a study performed by Boardley and Kavussanu ${ }^{26}$ the aim was to examine whether certain social variables, perceived social climate and character-building competency, and moral disengagement had any influence over prosocial and antisocial behaviors in field hockey and netball. The authors reported that previously performed research has shown that moral disengagement has the ability to override prosocial behaviors allowing people to commit morally unacceptable activities. Boardley and Kavussanu ${ }^{26}$ examined whether moral disengagement would inhibit the learning of character building competencies that would increase the prosocial, or morally acceptable, behaviors. Participants' consisted of both males and females $(N=155$ and $N$ $=224$, respectively). ${ }^{26}$ The results indicated that depending on how the athlete viewed his or her coach, as morally competent or incompetent, influenced the moral behaviors of the athletes. If the coach was considered to have high moral character the athlete was less likely to display antisocial behaviors, such as aggression, toward opponents. The authors ${ }^{26}$ stated that these results supported the previously established link between moral disengagement and moral behavior in sport. However, what was unique to this study was the use of the coach's moral influence over the athletes. ${ }^{26}$ The previously reviewed studies have solely focused on the athlete while the study performed by Boardley and 
Kavussanu ${ }^{26}$ included the athlete's view of the team's coach who are responsible for providing the athlete with a moral code.

Moral disengagement in sport has not been extensively examined. However, the measure has been studied in other settings including interpersonal relationships and the workforce. Examining moral disengagement in other setting will also demonstrate how these processes work and shape individuals moral behaviors. Moral disengagement in other settings

Moral disengagement has been extensively examined in a number of different settings and contexts including delinquent behavior, the likelihood of aggression and negative relationship to prosocial actions. ${ }^{27}$ By examining the processes of moral disengagement in a number of varied settings the goal was to show how the mechanisms function similarly regardless of the situation. A study performed by Hyde, Shaw and Moilanen ${ }^{65}$ examined some of the precursors of moral disengagement as the underlying for displayed antisocial behavior. The study focused on the link between moral disengagement and antisocial behavior, including displayed aggression. The study followed infant boys $(N=310)$ from the age of 1.5 years through age 17 living in an area that was considered to be high risk for antisocial outcomes such as participation in crimes including violence, theft, and gambling. ${ }^{65}$ These participants were born into a poor socioeconomic standing. The authors hypothesized that moral disengagement would play a major role in the development of antisocial behavior, including physical aggression towards others, later in life. ${ }^{65}$ The researchers utilized the Mechanisms of Moral Disengagement Scale and the Self-report of Delinquency Questionnaire to measure moral disengagement and antisocial behavior, respectively. The findings of this study indicated 
that there was a link between moral disengagement and antisocial behavior later in life by showing a minimal correlation $(r=.35) \cdot{ }^{67}$ The authors theorized that the development of moral disengagement may have allowed these immoral actions to occur. Further more empathy, which is considered the antagonist of aggression, was found to be low in those participants with high levels or moral disengagement. ${ }^{65}$ This showed that those participants that were more likely to aggress were demonstrating less empathy and higher levels of moral disengagement indicating that the process of self-regulation was being overridden. ${ }^{65}$

The research team of Paciello, Fida, Tramontano, Lupinetti and Capara ${ }^{62}$ conducted a similar study to the one previously discussed. The study examined whether moral disengagement remained stable or changed throughout adolescence and it's subsequent impact on aggression and violence. ${ }^{62}$ The design of this study was an ongoing longitudinal study that followed the participants, both males and females, from infancy into early adulthood. The study was composed of adolescents $(N=366)$ with both males $(N=177)$ and females $(N=189)$ located in an Italian suburb of Rome. The interview process occurred at five specific intervals: age $12,14,16,18$, and finally at $20{ }^{62}$ The study hypothesized that a relationship existed between the development of moral disengagement and aggression and violence in late adolescence or early adulthood. ${ }^{62}$ The researchers used various methods of examining the levels of moral disengagement and aggression that were age specific to their participants. When assessing moral disengagement the research team utilized the Moral Disengagement Scale and aggression by having the classmates rank each of their peers with a likelihood that the child would partake in some activity such as kicking or insulting other. ${ }^{62}$ 
Violence was measured by an 11-item self-report measure that prompted the participants to indicate how often they would take part in specific activities such as gang participation and fights. ${ }^{62}$

The results of the study showed that levels of moral disengagement decreased as the participants aged, specifically around high school age. ${ }^{62}$ However, this decrease was not seen in all groups indicating variances in moral development. Females were less likely to report high levels of moral disengagement. The statistical analysis indicated that a positive correlation existed between moral disengagement and aggressive and violent outcomes. ${ }^{62}$ More specifically these results mean that participants with elevated levels of high moral disengagement on the measure were shown to have higher rates of aggression and violent tendencies later in life indicating a relationship between the two variables. ${ }^{62}$

Another study linking violence and moral disengagement performed examined at the relationship to graphic media violence. ${ }^{68}$ The study wanted to determine if the presence of moral disengagement, termed in the research as a cognitive distortion, would cause an individual viewing violent media to have an increase acceptance and inclination toward aggressive behavior. ${ }^{68}$ They stated that those people with high levels of moral disengagement are typically less prosocial and therefore feel less remorse over their actions which in turn causes less restraint over their aggressive behavior. These weakened inhibitions, caused in part by the level of moral disengagement, perception of what in normal behavior can be greatly altered. The sample was composed of college undergraduates with both females $(N=35)$ and males $(N=51)$ with a mean age of 21.30 and 20.25 years, respectively. ${ }^{68}$ The samples were given three questionnaires the Frequency and Enjoyment of Violent Media Questionnaire, The Buss-Perry Aggression 
Questionnaire, and Mechanisms of Moral Disengagement Questionnaire. The finding of the study suggested that the level of aggression and perception of normal behavior could be greatly influenced by the mechanisms of moral disengagement. ${ }^{68}$ Via the mechanisms of moral disengagement, individuals can remove the blame from themselves allowing for participation in morally reprehensible actions. If the subject reports viewing a significant amount of violence during everyday life he/she is already desensitized and less likely to be effected morally. Therefore, disengaging morally from their behavior further increases likelihood.

Although, this study does not specifically examine aggression and moral disengagement in sport the research provided compelling evidence of the theoretical relationship. Those participants that were found to have the highest levels of moral disengagement were more likely to report incidents of aggression later in life. ${ }^{68}$ This finding indicates that the mechanisms of moral disengagement may allow for those participants to engage in aggressive behavior. The information attained from this study can be applied to athletics. ${ }^{68}$ The sample participants viewed an excessive amount of violent and aggressive behavior creating a scenario that furthered the acceptance and legitimacy of it. In athletics, aggressive actions are often performed and considered to be acceptable parts of the game. ${ }^{68}$ The perception that aggressive actions are defensible indicates that there are mechanisms of moral disengagement acting on the innate factors of moral self-regulation. ${ }^{68}$ Since the moral self is unable to regulate the actions while the mechanisms of moral disengagement are active the individual becomes more likely to engage in behavior that is deemed to be reprehensible. ${ }^{26}$ It is believed that this process 
allows individuals to transgress upon one another, such as is seen in children and adolescents that engage in bullying.

Bullying, which is defined as a sub-classification of aggression, is more often encountered in children and adolescents. ${ }^{69}$ Hymel, Rocke-Henderson, and Bonanno ${ }^{69}$ examined whether the construct of moral disengagement could explain the occurrence and provide an understanding for the commonality of bullying in society. The sample population included students $(N=494)$ both females $(N=216)$, males $(N=261)$. The participants completed a survey with a 73-item questionnaire that had various prompts about bullying. ${ }^{69}$ The findings of this study revealed that those participants that reported bullying extensively showed higher score on the measure for moral disengagement than those that reported engaging in bullying sometimes or never. The study indicated that up to $38 \%$ of the responses were explained using some mechanism of moral disengagement, most commonly cognitive restructuring and attribution of the blame. ${ }^{69}$ The bullies reported feeling that the kids they aggressed against were deserving of the treatment they received or that they were somehow at fault for an unknown offense. These evaluations that determined a probable link between moral disengagement and aggression were performed as posthoc analyses. ${ }^{69}$ The authors reported that the use of moral disengagement in childhood was alarming since these mechanisms will likely be used throughout adolescents and adulthood to justify aggressive conduct. It is this perpetuation of moral disengagement in youth plays a major role in later life. ${ }^{69}$

In a similar study conducted by Menesini and colleagues ${ }^{70}$ examining children that were identified as bullies, social outsiders, or the victims of bullying. The outsiders were defined as the children that were not identified as bullies or victims. The final 
sample consisted of participants $(N=197)$ aged nine years and 13 years. ${ }^{70}$ The researchers interviewed teachers and students to identify those children in their classes that were considered to be bullies and victims. Participants were then asked to assume the role of a bully in a number of situations. The findings of this study indicated that the children originally identified as bullies would employ the mechanisms of moral disengagement in the response to the prompts and allow them to act aggressively towards the characters in the story. ${ }^{70}$ The findings showed that the bullies were more able to justify their use of negative behavior and aggression towards other using the mechanism of moral disengagement. ${ }^{70}$ The results of these two studies clearly demonstrate that for children and adolescents to engage in aggressive behaviors, such as bullying, the mechanisms of moral disengagement need to be in play to allow the child to assume the role of an intimidator. ${ }^{70}$ When assuming the role of the aggressor in a situation if one is to override an accepted moral code it is necessary to disengage themselves from the action and the consequences. ${ }^{70}$ The role of a bully is comparable to one of an aggressive athlete on the field and its likely that moral disengagement functions similarly. In addition to the classroom moral disengagement has been examined in many other settings that involve participation in actions that would be considered to be moral reprehensible.

Osofsky, Bandura, and Zimbardo ${ }^{63}$ examined moral disengagement in relationship to the process of a state execution. This study highlighted the process of moral disengagement in a specific setting. The researchers examined how the psyche must operate to perform an action that most people generally consider to be immoral and reprehensible. The study used personnel from three different prisons that participated in execution $(N=246)$ with a majority of the sample being male.$^{63}$ The participants of the 
study were given the 19-item questionnaire that was especially created for this group of subjects that dealt specifically with the execution process. The findings indicated that the processes of moral disengagement found to be most active were dehumanization, displacement and diffusion of responsibility in those participants of the executions. ${ }^{63}$ According to the authors these processes worked in concert with one another to allow the executioners to carry out their jobs. Those participants not directly involved in the process of an execution such as the other guards working at the prison or support teams were found to have a much lower level of moral disengagement. ${ }^{63}$ When examining these participants the authors ${ }^{63}$ created a measure specifically for this setting; one of the most important aspects is the ability to measure and quantify the variable in question. By having a valid and reliable questionnaire to assess the participants researchers can examine theoretical constructs that cannot be objectively measured.

Measuring moral disengagement

Various scales have been created to measure moral disengagement for each context examined including interpersonal aggression, social responsibilities, and personal views of military action. These scales have each been created for individual contexts. As a result the Moral Disengagement in Sport Scale (MDSS) was created by Boardley and Kavussanu ${ }^{27}$ as a method to measure moral disengagement in sport since other scales could not adequately cover this topic. It has been argued that the strength of the association between moral disengagement and transgressions in various settings require that multiple measures be created since each one respectively focuses on behaviors that may be specific to a setting. ${ }^{27}$ 
Boardley and Kavssanu ${ }^{27}$ performed a two-part study to develop and validate their newly created measure. The goal of the original study was to create a scale that would be specific to sports and have acceptable validity and reliability. The first phase of the study was designed to create a measure utilizing a group of participants $(N=308)$, ranging in age from 12 to 68 years old. These participants were members of soccer, rugby, netball, hockey, and basketball teams. The questions included items to assess all eight mechanisms of moral disengagement and was designed as a prompt that the athlete rated himself or herself on a 5-point Likert scale ranging from -2 (not at all representative) to +2 (extremely representative). Some examples of items included on the measure are "Mocking an opponent is not bad compared to injuring him/her" to measure advantageous comparison or "It is okay to be hostile to an opponent who has insulted your teammate/s" which is intended to measure moral justification. ${ }^{27}$

After examining the confirmatory factor analyses the final results showed their 59-item measure to adequately measure moral disengagement in sport. The research showed that the mechanisms of moral disengagement were highly active during sport participation due to the amount that was reported by the participants. Using their newly created scale, Boardley and Kavussanu, ${ }^{27}$ reported that males displayed higher levels of moral disengagement that the female participants. The athletes that were participating in soccer and rugby were more morally disengaged than those participating in hockey or basketball. Their research also indicated that age was negatively correlated with levels of moral disengagement; therefore, showing that older participants show less signs of moral disengagement. ${ }^{27}$ 
The second part of Boardley and Kavussanu ${ }^{27}$ experiment was to determine the validity of the measure. The second study included male $(N=217)$ and females $(N=88)$ aged 12 through 55 years old participating in soccer, netball, hockey, rugby, and basketball at various competitive clubs and universities in central and northern England. ${ }^{27}$ The second MDSS was only composed of 40 items; 38 items were from the original study that best represented moral disengagement in sport and two more that had be restructured as a result from the previous experiment. The findings of this part of the study showed that the MDSS had acceptable reliability and validity for measuring moral disengagement in athletics. ${ }^{27}$ Using other measures of moral disengagement including the Moral Disengagement in Society and Prosocial and Antisocial Behavior in Sport the validity of the MDSS can be determined. The analysis of the measure revealed a correlation of $\mathrm{r}=.71$ which has been determined to be acceptable; if this number was higher than $r=.90$ the measure would be considered to be redundant and therefore not useful. The reliability of the MDSS was determined to range from .73 to .95 , indicating that the measure has an acceptable to very good level of reliability. ${ }^{27}$ The final composition of the MDSS is a 32-item scale with four prompts measuring each of the eight mechanisms of moral disengagement. The authors examined the factor loading and error variances values of the items which resulting the removal of eight items resulting in the 32 -item scale that is used today. ${ }^{27}$

\section{CONCLUSION}

The relationship between the level of trait aggression and injury rate has not been extensively examined in the literature. As previously described there are few studies that examined this topic and the results were somewhat conflicting; Emery and 
colleagues ${ }^{7}$ found no relationship between trait aggression and reported injury rates while Thompson and Morris ${ }^{5}$ stated that those individuals with either too little or too much aggression were more at risk. This relationship may be important to sports medicine professionals and sports psychologists in an effort to prevent injury. Identifying athletes that may be predisposed to becoming injured or harming others during sports participation would theoretically allow for intervention strategies to be incorporated into the athletes' routines. Furthermore, by investigating the relationship between moral disengagement and trait aggression the moral reasoning behind the athletes' actions will be determined. This investigation will also provide more information about the use of the processes of moral disengagement during sport participation and how they affect the athlete's behaviors. As a result the purpose of this investigation is two-fold. First will be to examine whether a relationship exists between the levels of trait aggression and injury rates. Second moral disengagement will be examined as a predecessor of aggression in athletes. 


\section{APPENDIX C}

\section{REFERENCES}

1. Murphy P, Waddington I. Sport for all: Some public health policy issues and problems. Critical Public Health. 1998;8(3):193-205.

2. Hootman JM, Dick R, Agel J. Epidemiology of collegiate injuries for 15 sports: Summary and recommendations for injury prevention initiatives. $J$ Athl Training. 2007;42(2):311-19.

3. Emery CA, Meeuwisse WH. Injury rates, risk factor, and mechanisms of injury in minor hockey. Am J Sports Med. 2006;34:1960-69.

4. Kimble NB, Russo SA, Bergman BG, Galindo VH. Revealing an empirical understanding of aggression and violent behavior in athletics. Aggress Violent Beh. 2010.

5. Thompson NJ, Morris RD. Predicting injury risk in adolescent football players: The importance of psychological variables. J Pediatr Psychol. 1994;19(4):415-29.

6. Fields KB, Delaney M, Hinkle JS. A prospective study of type a behavior and running injuries. J Fam Pract. 1990;30:425-429.

7. Emery CA, McKay CD, Campbell TS, Peters AN. Examining attitudes toward body checking, levels of emotional empathy, and levels of aggression in body checking and non-body checking youth hockey leagues. Clin J Sports Med. 2009;19(3):207-15.

8. Williams JM, Andersen MB. Psychosocial antecedents of sport injury: Review and critique of the stress injury model. J Appl Sport Psychol. 1998;10(1):5-25.

9. Lavallee L, Flint F. The relationship of stress, competitive anxiety, mood state, and social support to athletic injury. J Athl Train. 1996;31(4):296-99.

10. Chantal Y, Robin P, Vernat JP, Bernache-Assollant I. Motivation, sportspersonship, and athletic aggression: A meditational analysis. $J$ Sport Exercise Psy. 2005;6:233-249.

11. Pappas NT, McKenry PC, Skilken-Catlett B. Athlete aggression on the rink and off the ice. Men and Masculinities. 2004;6(3):291-321.

12. Rascle O, Traclet A, Souchon N, Coulomb-Cabagno G, Petrucci C. Aggressorvictim dissent in the perceived legitimacy of aggression in soccer: The moderating role of situational background. Res Q Exercise Sport. 2010;81(3):34048. 
13. Maxwell JP, Visek AJ. Unsanctioned aggression in rugby union: Relationships among aggressiveness, anger, athletic identity, and professionalization. Aggressive Behav. 2009;35:237-43.

14. Maxwell JP, Visek AJ, Moores E. Anger and perceived legitimacy of aggression in male hong kong Chinese athletes: Effects of type of sport and level of competition. Psychology of Sport and Exercise. 2009;10:289-96.

15. Gee CJ, Leith LM. Aggressive behavior in professional ice hockey: A crosscultural comparison of north American and European born NHL players. Psychology of Sport and Exercise. 2007;8:567-83.

16. Buss AH, Perry M. The aggression questionnaire. J Pers Soc Psychol. 1992;63(3):452-459.

17. Bushman BJ, Wells GL. Trait aggressiveness and hockey penalties: Predicting hot tempers on the ice. J Appl Psychol. 1998;83(6):969-74.

18. Anestis MD, Anestis JC, Selby EA, Joiner TE. Anger rumination across forms of aggression. Pers Indiv Differ. 2009;46:192-6.

19. Junge A. The influence of psychological factors on sports injuries: Review of the literature. Am J Sports Med. 2000;28:S-10-5.

20. Locke KD. Aggression, narcissism, self-esteem, and the attribution of desirable and humanizing traits to self versus others. J Res Pers. 2009;43:99-102.

21. Lavarda A. Contributo allo studio della dendenza psicologica agli infortuni nello sport. Int J Sport Psychol. 1975;6:215-218.

22. Long T, Pataléon N, Bruant G, d'Arripe-Longueville F. A qualitative study of moral reasoning of young elite athletes. Sport Psychol. 2006;20:330-47.

23. Corrion K, Long T, Smith AL, d'Arripe-Longueville F. "It's not my fault; it's not serious": Athlete accounts of moral disengagement in competitive sport. Sport Psychol. 2009;23:388-404.

24. Bandura A. Selective moral disengagement in the exercise of moral agency. $J$ Moral Educ. 2002;31(2):101-19.

25. Kavussanu M. Moral behaviour in sport: a critical review of the literature. International Review of Sport and Exercise Psychology. 2008;1(2):124-38. 
26. Boardley ID, Kavussanu M. The influence of social variables and moral disengagement on prosocial and antisocial behaviours in field hockey and netball. J Sport Sci. 2009;27(8):843-54.

27. Boardley ID, Kavussanu M. Development and validation of the moral disengagement in sport scale. J Sport Exercise Psy. 2007;29:608-28.

28. Maxwell JP, Moores E. The development of a short scale measuring aggressiveness and anger in competitive athletes. Psychology of Sport and Exercise. 2007;8:179-93.

29. Brunelle JP, Janelle CM, Tennant LK. Controlling competitive anger among male soccer players. J Appl Sport Psychol. 1999;11(2): 283-97.

30. Berkowitz L. Frustration-aggression hypothesis: Examination and reformulation. Psychol Bull. 1989;106(1):59-73

31. Eagly AH, Steffen VJ. Gender and aggressive behavior: A meta-analytic review of the social psychological literature. Psychol Bull. 1986;100(3):309-30.

32. Anderson CA, Bushman BJ. Human aggression. Annu. Rev. Psychol. 2002;53:2751.

33. Donahue EG, Rip B, Vallerand RJ. When winning is everything: On passion, identity, and aggression in sport. Psychology of Sport and Exercise. 2009;10:52634.

34. Archer J, Webb IA. The relation between scores on the buss-perry aggression questionnaire and aggressive acts, impulsiveness, competitiveness, dominance and sexual jealousy. Aggressive Behav. 2006;32:464-73.

35. Leith LM. The effect of various physical activities, outcome, and emotional arousal on subject aggression scores. Int J Sport Psychol. 1989;20(1):57-66.

36. Huessmann LR. An information-processing model for the development of aggression. Aggress. Behav. 14:12-24.

37. Anderson CA, Dill KE. Video games and aggressive thoughts, feelings, and behavior in the laboratory and in life. J Pers Soc Psychol. 2000;78(4):772-90.

38. Burton LA, Hafetz J, Henninger D. Gender differences in relational and physical aggression. Soc Behav Personal. 2007;35(1):41-50.

39. Gidycz CA, Warkentin JB, Orchowski LM. Predictors of perpetration of verbal, physical, and sexual violence: A prospective analysis of college men. Psychology of Men \& Masculinity. 2007;8(2): 79-94. 
40. Betensky JD, Contrada RJ. Depressive symptoms, trait aggression, and cardiovascular reactivity to a laboratory stressor. Ann Behav Med. 2010;39:18491.

41. Archer J, Thanzami V. The relation between physical aggression, size, and strength, among a sample of young Indian men. Pers Indiv Differ. 2007;43:62733.

42. Suris A, Lind L, Emmett G, et al. Measures of aggressive behavior: Overview of clinical and research instruments. Aggress Violent Beh. 2004;9(2):165-227.

43. Buss AH, Durkee A. An inventory for assessing different kinds of hostility. Journal of Consulting Psychology. 1957;24:349-54.

44. Bredemeier B. The assessment of reactive and instrumental aggression. In I.D.M. Landers (Ed.), Psychology of sport and motor behavior II. State College, PA: Penn State HPER Series. 1975;71-84.

45. Bredemeier B. Moral reasoning and the perceived legitimacy of intentionally injurious sport acts. J Appl Sport Psychol. 1978;7:110-124.

46. Conroy DE, Silva JM, Newcomer RR, Walker BW, Johnson MS. Personal and participatory socializers of the perceived legitimacy of aggressive behavior in sport. Aggressive Behav. 2001;27:405-18.

47. Chow GM, Murray KE, Feltz DL. Individual, team, and coach predictors of players likelihood to aggress in youth soccer. J Sport Exercise Psy. 2009;31:42543.

48. VaezMousavi SM, Shojaei M. Association between coaches' behaviors and players' aggressive and assertive actions. International Journal of Applied Sports Sciences. 2005;17(2):35-43.

49. Schwebel DC, Banaszek MM, McDaniel M. Brief report: Behavioral risk factors for youth soccer (football) injury. J Pediatr Psychol. 2007;32(4):411-16.

50. Arnold PJ. Sport, moral development, and the role of the teacher: Implications for research and moral education. Quest. 2001;53:135-50.

51. Kohlberg L, Hersh RH. Moral development: A review of the theory. Theor Pract. 1977;16(2):53-9.

52. Haan N, Smith MB, Block J. Moral reasoning of young adults: Political-social behavior, family background, and personality correlates. J Pers Soc Psychol. 1968;10(3):183-201. 
53. Bredemeier BJL. Children's moral reasoning and their assertive aggressive, and submissive tendencies in sport and daily life. J Sport Exercise Psy. 1994;16:1-14.

54. Haan N. Two moralities in action contexts: Relationships to thought, ego regulation and development. J Pers Soc Psychol. 1978;36(3):286-305.

55. Proios M. Development and validation of a questionnaire for the assessment of moral content judgment in sport. IJSEP. 2010;7:189-210.

56. Jones $\mathrm{C}$, McNamee M. Moral reasoning, moral action, and the moral atmosphere of sport. Sport Educ Soc. 2000;5(2):131-46.

57. Bredemeier BJ, Shields DL. Moral growth among athletes and nonathletes: A comparative analysis. J Genet Psychol. 2001;147(1):7-18.

58. Camrié M, Trudel P. High school athletes perspectives on character development through sport participation. Physical Education and Sport Pedagogy. 2010;15(2):193-207.

59. Skelton C. 'A passion for football': Dominant masculinities and primary schooling. Sport Educ Soc. 2001;5(1):5-18.

60. Sage LD, Kavussanu M. Goal orientations, motivational climate, and prosocial and antisocial behaviour in youth football: Exploring their temporal stability and reciprocal relationships. Journal of Sport Sciences. 2008;26(7):717-32.

61. McAlister AL. Moral disengagement: Measurement and modification. J Peace Res. 2001;38(1):87-99.

62. Paciello M, Fida R, Tramontano C, Lupinetti C, Caprara GV. Stability and change of moral disengagement and its impact on aggression and violence in late adolescence. Child Dev. 2008;79(5):1288-309.

63. Osofky MJ, Bandura A, Zimbardo PG. The role of moral disengagement in the execution process. Law Human Behav. 2005;29(4):371-88.

64. O'Leary-Kelly AM, Paetzold RL, Griffin RW. Sexual harassment as aggressive behavior: An actor-based perspective. Acad Manage Rev. 2000;25(2);372-88.

65. Hyde LW, Shaw DS, Moilanen KL. Developmental precursors of moral disengagement and the role of moral disengagement in the development of antisocial behavior. J Abnorm Child Psychol. 2010;28:197-209.

66. Widmeyer WN, Birch JS. Aggression in professional ice hockey: A strategy for success or a reaction to failure? J Psychol. 1984;117:77-84. 
67. Domholdt E. Rehabilitation Research: Principles and Applications. $3^{\text {rd }}$ ed. Philadelphia: Elsevier Saunders: 2005.

68. Richmond J, Wilson JC. Are graphic media violence, aggression and moral disengagement related? Psychiatry, Psychology, and Law. 2008;15(2):350-57.

69. Hymel S, Rocke-Henderson N, Bonanno RA. Moral disengagement: a framework for understanding bullying among adolescents. J Soc Sci. 2005;8:1-11.

70. Menesini E, Sanchez V, Fonzi A, Ortega R, Costabile A, Feudo GL. Moral emotions and bullying: A cross-national comparison of differences between bullies, victims and outsiders. Aggressive Behav. 2003;29:515-30. 


\section{APPENDIX D}

IRB APPROVAL

Located on the next page. 

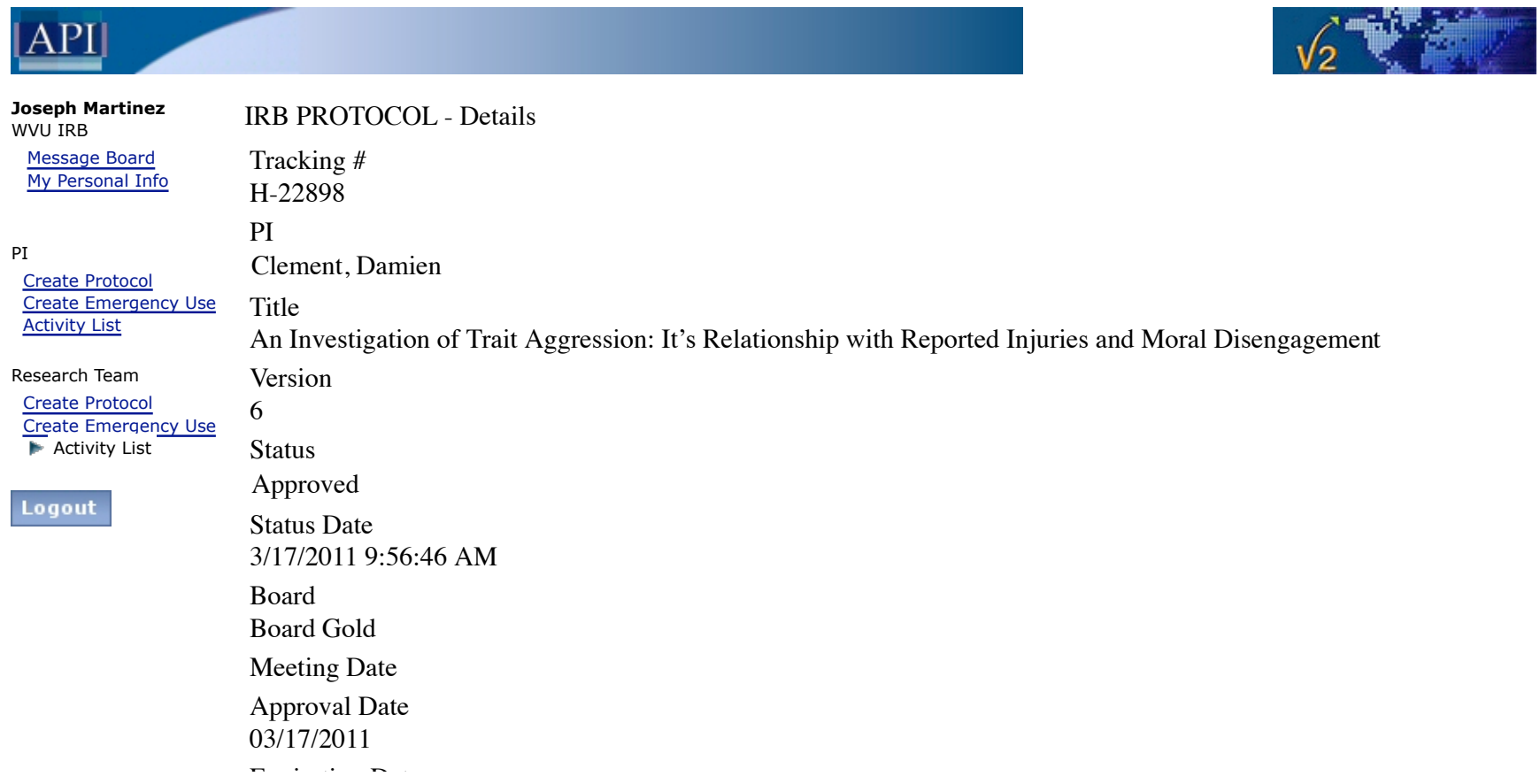


\section{APPENDIX E}

Competitive Anger and Aggressiveness Scale

Please rate each of the following items in terms of how characteristic they are of you. Use the following scale for answering these items.

$1=$ almost never, $2=$ occasionally, $3=$ sometimes, $4=$ quite often, $5=$ almost always

1. I become irritable if I am disadvantaged during a match

$\begin{array}{lllll}1 & 2 & 3 & 4 & 5\end{array}$

2. I feel bitter toward my opponent if I lose

$\begin{array}{lllll}1 & 2 & 3 & 4 & 5\end{array}$

3. I get mad when I lose points

$\begin{array}{lllll}1 & 2 & 3 & 4 & 5\end{array}$

4. I show my irritation when frustrated during a game
12
3
$4 \quad 5$

5. I find it difficult to control my temper during a match
12
3
4
5

6. Official's mistakes make me angry

$\begin{array}{lllll}1 & 2 & 3 & 4 & 5\end{array}$

7. Violent behaviour, directed toward an opponent, is acceptable
1
2
34
5

8. It is acceptable to use illegal physical force to gain an advantage
1
2
3
4
5

9. I taunt my opponents to make them lose concentration
12
3
45

10. I use excessive force to gain an advantage
1
2
3
4
5

11. I verbally insult opponents to distract them
12
3
4
5

12. Opponents accept a certain degree of abuse
1
2
3
4
5 


\section{APPENDIX F}

Moral Disengagement in Sport Scale

Please rate each of the following items in terms of how characteristic they are of you. Use the following scale for answering these items.

$\begin{array}{lllllcc}1 & 2 & 3 & 4 & 5 & 6 & \begin{array}{c}7 \\ \text { I strongly } \\ \text { agree } \\ \text { disagree }\end{array}\end{array}$

1. It is okay to be hostile to an opponent who has insulted your teammate/s
1
23
4
5
6
7

2. It is okay for players to lie to officials if it helps their team.
1
2
3
4
5
6
7

3. Fouling an opponent is okay if it discourages him/her from injuring your teammates.
1
2
3
$4 \quad 5$
6
7

4. Fighting is okay if it is one to protect a teammate.
1
2
3
4
5
6
7

5. Injuring an opponent is a way of teaching him/her a lesson.

$\begin{array}{lllllll}1 & 2 & 3 & 4 & 5 & 6 & 7\end{array}$

6. Bending the rules is a way of evening thing up.
1
2
3
45
6
7

7. Acting aggressively is just a way of showing you are a tough opponent.
1
2
4
6
7

8. Arguing with officials is a way of keeping them on their toes.
1
2
3
4
5
6
7

9. Mocking an opponent is not bad compared to injuring him/her.
1
2
3
$4 \quad 5$
6
7

10. Compared to physical violence, verbally provoking an opponent is not that bad.
1
2
3
4
6
7

11. Shouting at an opponent is okay as long as it does not end in violent conduct.
1
2
3
4
5
6
7 
12. Winding an opponent up is nothing compared to screaming abuse in his/her face. $\begin{array}{lllllll}1 & 2 & 3 & 4 & 5 & 6 & 7\end{array}$

13. A player should not be blamed for using illegal tactics if everyone on the team is doing it.
1
2
3
4
5
6
7

14. It is unfair to blame players who only play a small part in unsportsmanlike tactics used by their team.
1
23
4
$5 \quad 6$
7

15. A team decision to use unsportsmanlike tactics is jus that, and not the responsibility of any individual on the team.
1
3
$4 \quad 5$
6
7

16. Players should not take responsibility for negative consequences of their actions if they are following team decisions.
1
2
3
4
$5 \quad 6$
7

17. A player is not responsible for acting aggressively if this is encouraged by his/her parents.

$\begin{array}{lllllll}1 & 2 & 3 & 4 & 5 & 6 & 7\end{array}$

18. A player should not be blamed for injuring an opponent if the coach reinforces such behavior.

$\begin{array}{lllllll}1 & 2 & 3 & 4 & 5 & 6 & 7\end{array}$

19. If players are not disciplined for unsportsmanlike conduct they should not be blamed for behaving this way.
1
23
4
$5 \quad 6$
7

20. A player should not be blamed for arguing with officials if he/she has seen the coach doing it.

$\begin{array}{llllllll}1 & 2 & 3 & 4 & 5 & 6 & 7\end{array}$

21. Mocking an opponent does not really hurt him/her.

$\begin{array}{llllllll}1 & 2 & 3 & 4 & 5 & 6 & 7\end{array}$

22. Insults among players do not really hurt anyone.
1
23
4
5
6
7

23. Aggressive language toward an opponent does not actually harm anyone.
1
2
3
4
5
6
7

24. Teasing an opponent does not really hurt him/her.

$\begin{array}{llllllll}1 & 2 & 3 & 4 & 5 & 6 & 7\end{array}$


25. Some opponents deserve to be treated like animals.

$\begin{array}{llllllll}1 & 2 & 3 & 4 & 5 & 6 & 7\end{array}$

26. It is okay to treat badly an opponent who behaves like an animal.
1
2
3
$4 \quad 5$
6
7

27. If an opponent acts like an animal he/she deserves to be treated like one.

$\begin{array}{lllllll}1 & 2 & 3 & 4 & 5 & 6 & 7\end{array}$

28. If an opponent ides not act humanly he/she should be made to suffer.

$\begin{array}{lllllll}1 & 2 & 3 & 4 & 5 & 6 & 7\end{array}$

29. If an opponent mocks a player, it is the opponent's fault if the player then tries to injury him/her.

$\begin{array}{llllllll}1 & 2 & 3 & 4 & 5 & 6 & 7\end{array}$

30. Players who get mistreated have usually done something to deserve it.

$\begin{array}{lllllll}1 & 2 & 3 & 4 & 5 & 6 & 7\end{array}$

31. If a player retaliates to something an opponent has done, it is the opponent's fault.

$\begin{array}{lllllll}1 & 2 & 3 & 4 & 5 & 6 & 7\end{array}$

32. A player should not be held responsible if he/she retaliates when fouled.

$\begin{array}{lllllll}1 & 2 & 3 & 4 & 5 & 6 & 7\end{array}$




\section{APPENDIX G \\ Demographic Information}

The following questionnaire is to obtain general information. Please answer the questions as truthfully as possible. Thank you.

1. What is your sex?
a. Male
b. Female

2. What year were you born?

a.

3. What year are you in college?
a. Freshman
b. Sophomore
c. Junior
d. Senior
e. Fifth Year Student

4. What sport do/did you most recently participate in at Waynesburg University?
a. Football
b. Wrestling
c. Soccer
d. Basketball

5. What position do you play? (Wrestlers: What class (or classes) do you wrestle?)

a.

6. How many injuries did you report to the athletic trainers during the season? Please count only those injuries sustained during either practice or games.

a.

7. During the season did you sustain an injury that prevented you from completing your season?
a. Yes
b. No 


\section{APPENDIX H}

Consent and Information Page

Located on the next page. 


\section{WestVirginiaUniversity.}

Office of Research Compliance

\section{CONSENT AND INFORMATION FORM}

OMR ICF

Principal Investigator: Clement, Damien

Department: Physical Education

Tracking Number: $\quad \mathrm{H}-22898$

\section{Study Title:}

An Investigation of Trait Aggression: It's Relationship with Reported Injuries and Moral Disengagement

\section{Co-Investigator(s):}

Martinez, Joseph

\section{Sponsor}

\section{Contact Persons}

If you have any questions, concerns, or complaints about this research, you can contact Joseph Martinez, ATC at 908/619-5424 or Dr. Damien Clement at 304/293-0863

For information regarding your rights as a research subject, you may contact the Office of Research Compliance at 304/293-7073.

\section{Introduction}

In addition if you would like to discuss problems, concerns, have suggestions related to research, or would like to offer input about the research, contact the Office of Research Integrity and Compliance at 304293-7073.

You, have been asked to participate in this research study, which has been explained to you by Joseph Martinez, ATC.

\begin{tabular}{lll}
\hline Tracking \#: & $\mathrm{H}-22898$ & Page 1 of 6 \\
Approved On: & $03 / 17 / 2011$ & \\
Valid Through: & $03 / 16 / 2012$ & \\
Last Amended: & N/A &
\end{tabular}


This study is being conducted by Joseph Martinez, ATC in the Department of Athletic Training at West Virginia University. This research is being conducted to fulfill the requirements for a Masters Thesis in Athletic Training in the Department of Sport Sciences at West Virginia University, under the supervision of Dr. Damien Clement, ATC.

\section{Purposes of the Study}

The purpose of this study is to learn more about the relationship between aggression, injury rates and moral reasoning.

\section{Description of Procedures}

This study involves answering the questionnaires and will take approximately 10-15 minutes for you to complete. Approximately 127 subjects will be enrolled in this study. You will be asked to fill out questionnaires regarding basic descriptive information, aggression in personality, and moral reasoning. You do not have to answer all the questions. You will have the opportunity to see the questionnaire before signing this consent form. The second part of this research will involve me examining your medical records and counting the number of reported injuries. No other identifiable information will be obtained from your record. All information that is obtained in this research will be kept confidential so please answer truthfully as possible.

\section{Risks and Discomforts}

There are no known or expected risks from participating in this study, except for the mild frustration associated with answering the questions.

\section{Alternatives}

You do not have to participate in this study.

\section{Benefits}

You may not receive any direct benefit from this study. The knowledge gained from this study may eventually benefit others.

\begin{tabular}{lllll}
\hline Tracking \#: & $\mathrm{H}-22898$ & Page 2 of 6 & \\
Approved On: & $03 / 17 / 2011$ & & & \\
Valid Through: & $03 / 16 / 2012$ & & & \\
Last Amended: & N/A & & & \\
\end{tabular}




\section{Financial Considerations}

Participants will incur no cost by being involved with this study.

Furthermore, they will not be paid, not receive class credit or have their class or team status affected by participating in the study.

\section{Confidentiality}

Any information about you that is obtained as a result of your participation in this research will be kept as confidential as legally possible. Your research records and test results, just like hospital records, may be subpoenaed by court order or may be inspected by federal regulatory authorities without your additional consent.

In any publications that result from this research, neither your name nor any information from which you might be identified will be published without your consent.

We know that information about you and your health is private. We are dedicated to protecting the privacy of that information. Because of this promise, we must get your written authorization before we may use or disclose your protected health information or share it with others for research purposes.

You can decide to sign or not to sign this authorization section. However, if you choose not to sign this authorization, you will not be able to take part in the research study. Whatever choice you make about this research study, it will not have an effect on your access to medical care.

Persons/Organizations providing the information: Athlete/Waynesburg University Sports Medicine Department

\section{Persons/Organizations receiving the information:}

- The research site(s) carrying out this study. This includes UHA or UHA Affiliated, WVU, WVU Hospitals. It also includes each site's research staff and medical staff.

The following information will be used:

Information from your existing medical records and new information about

\begin{tabular}{lllll}
\hline Tracking \#: & $\mathrm{H}-22898$ & Page 3 of 6 & & \\
Approved On: & $03 / 17 / 2011$ & & & Date \\
Valid Through: & $03 / 16 / 2012$ & & & \\
Last Amended: & N/A & & &
\end{tabular}


you that is created or collected during the study such as: Number of injuries reported to the athletic training staff at Waynesburg University

The information is being disclosed for the following reasons:

- Publication of study results

\section{You may cancel this authorization at any time by writing to the Principal Investigator: (College of Physical Activity and Sport Sciences. PO Box 6116, Morgantown, WV 26506)}

If you cancel this authorization, any information that was collected already for this study cannot be withdrawn. Once information is disclosed, according to this authorization the recipient may redisclose it and then the information may no longer be protected by federal privacy regulations.

You have a right to see and make copies of your medical records. You will not be able to see or copy your records related to the study until the sponsor has completed all work related to the study. At that time you may ask to see the study doctor's files related to your participation in the study and have the study doctor correct any information about you that is wrong.

This authorization will not expire unless you cancel it.

\section{SIGNATURE}

I have read this section and all of my questions have been answered. By signing below, I acknowledge that I have read and accept all of the above.

\section{Voluntary Participation}

Participation in this study is voluntary. You are free to withdraw your consent to participate in this study at any time. Refusal to participate or withdrawal will not affect your future care, status as an athlete at Waynesburg University, and will involve no penalty to you. In the event new information becomes available that may affect your willingness to participate in this study, this information will be given to you so that you can make an informed decision about whether or not to continue your participation. You have been given the opportunity to ask questions about

\begin{tabular}{lllll}
\hline Tracking \#: & $\mathrm{H}-22898$ & Page 4 of 6 & & \\
Approved On: & $03 / 17 / 2011$ & & & Date \\
Valid Through: & $03 / 16 / 2012$ & & & \\
Last Amended: & N/A & & &
\end{tabular}


Tracking \#:

$\mathrm{H}-22898$

the research, and you have received answers concerning areas you did not understand.

$\begin{array}{lll}\text { Tracking \#: } & \mathrm{H}-22898 & \text { Page } 5 \text { of } 6 \\ \text { Approved On: } & 03 / 17 / 2011 & \\ \text { Valid Through: } & 03 / 16 / 2012 & \\ \text { Last Amended: } & \text { N/A } & \end{array}$


Upon signing this form, you will receive a copy.

I willingly consent to participate in this research.

\begin{tabular}{llll}
\hline $\begin{array}{l}\text { Signature of Subject or } \\
\text { Subjects Legal Representative }\end{array}$ & Date & & Timed Name
\end{tabular}

The participant has had the opportunity to have questions addressed. The participant willingly agrees to be in the study.

Signature of Investigator or

Printed Name

Date

Time

Co-Investigator

$\begin{array}{lll}\text { Tracking \#: } & \mathrm{H}-22898 & \text { Page } 6 \text { of } 6 \\ \text { Approved On: } & 03 / 17 / 2011 & \\ \text { Valid Through: } & 03 / 16 / 2012 & \\ \text { Last Amended: } & \text { N/A } & \end{array}$

$\overline{\text { Initials }} \quad \overline{\text { Date }}$

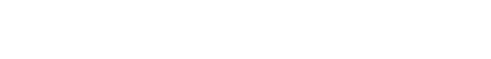

